\section{A) Check for updates}

Cite this: Food Funct., 2021, 12, 7358

\title{
In vitro gastrointestinal digestion impact on stability, bioaccessibility and antioxidant activity of polyphenols from wild and commercial blackberries (Rubus spp.)
}

\author{
Oscar Abel Sánchez-Velázquez, (DD a Miquel Mulero, (D) b \\ Edith Oliva Cuevas-Rodríguez, (DD a,c Martin Mondor, (D) d,e Yves Arcand (iD) and \\ Alan Javier Hernández-Álvarez (D) *f
}

\begin{abstract}
Gastrointestinal digestion (GID) is a physiological process that transforms the stability, bioaccessibility and antioxidant activity (AOX) of polyphenols from blackberries (Rubus spp.). This study aimed to investigate the effect of the INFOGEST $\circledast$ GID protocol on the phenolic stability, bioaccessibility and AOX of Mexican wild (WB) and commercial (CB) blackberries. After GID, the total phenolic and anthocyanin contents in blackberries decreased by $\geq 68 \%$ and $\geq 74 \%$, respectively. More than 40 phenolics were identified during GID; most of them degraded completely during digestion. GID had a negative effect on the AOX of both fruits ( $>50 \%$, but WB showed the highest antioxidant activities, as assessed by the ORAC, DPPH, reducing power and $\beta$-carotene bleaching methods. In Caco-2 cells, the cell-based antioxidant activity of digested blackberries $(p<0.05)$ decreased by $48 \%$ in WB and by $56 \%$ in CB. The capacity to inhibit intracellular ROS decreased by $50 \%$ in WB and by up to $86 \%$ in CB, after digestion. GID is a complex process that impacts on the bioactive properties of food nutrients, especially phenolics. In vitro and cellular AOX of WB polyphenols withstood the gastrointestinal environment better than CB phenolics. The in vitro assays results suggest that phenolics from underutilized WB have a higher bioaccessibility and antioxidant capacity than the polyphenols from the most frequently consumed CB. However, whether this corresponds to a better bioaccessibility in humans remains to be determined in future work.
\end{abstract}

Received 1st April 2021, Accepted 1st June 2021 DOI: $10.1039 / \mathrm{d} 1 \mathrm{fo} 00986 \mathrm{a}$ rsc.li/food-function

\section{Introduction}

Blackberries (Rubus spp.) are a large group of fruits with a rich diversity of bioactive polyphenols, such as phenolic acids, flavonoids and tannins. ${ }^{1}$ The phenolic profile of blackberries is closely related to biotic and abiotic stimuli, resulting in some important differences between wild species and cultivated

\footnotetext{
${ }^{a}$ Programa Regional de Posgrado en Biotecnología; Facultad de Ciencias QuímicoBiológicas, Universidad Autónoma de Sinaloa. Av. Josefa Ortíz de Dominguez, s/n, Ciudad Universitaria, PC 80030 Culiacán Rosales, Sinaloa, Mexico

${ }^{b}$ Nutrigenomics Research Group, Departament de Bioquimica i Biotecnologia, Universitat Rovira i Virgili, 43007 Tarragona, Spain

${ }^{{ }^{C} P o s g r a d o ~ e n ~ C i e n c i a ~ y ~ T e c n o l o g i ́ a ~ d e ~ A l i m e n t o s, ~ F a c u l t a d ~ d e ~ C i e n c i a s ~ Q u i m i c o-~}$ Biológicas, Universidad Autónoma de Sinaloa. Av. Josefa Ortíz de Dominguez, s/n, Ciudad Universitaria, PC 80030 Culiacán Rosales, Sinaloa, Mexico

${ }^{d}$ St-Hyacinthe Research and Development Centre, Agriculture and Agri-Food Canada, 3600 Casavant West Boulevard, Saint-Hyacinthe, Quebec, J2S 8E3, Canada ${ }^{e}$ Institute of Nutrition and Functional Foods (INAF), Université Laval, Quebec City, G1V 0A6 Quebec, Canada

${ }^{f}$ School of Food Science \& Nutrition, University of Leeds, LS2 9JT Leeds, UK.

E-mail:a.j.hernandezalvarez@leeds.ac.uk
}

species. In Mexico, wild blackberries and other Rosaceae berries are underutilized seasonal food sources collected only by inhabitants of remote mountainous regions and of minor economic importance, which are consumed as fresh fruits or processed for consumption in traditional dishes and beverages. ${ }^{2,3}$ Wild blackberries, although reported to have a higher phenolic content and biological effects, are scarcely consumed as edible fruits in comparison with commercial blackberries. ${ }^{4}$ Blackberries contain phenolic compounds, which have health promoting effects, such as excellent chemopreventive and chemotherapeutic effects and protection against chronic and non-chronic diseases. ${ }^{5,6}$ However, the health benefits of dietary phenolics are dependent on their bioaccessibility during gastrointestinal digestion (GID). ${ }^{7-9}$

In blackberries, different hydroxycinnamic and hydroxybenzoic acids are present in free forms, but they are mainly found as blocks of polymeric polyphenols, such as proanthocyanidins and hydrolysable tannins. ${ }^{10}$ In contrast, flavonoid derivatives, which have a characteristic C6-C3-C6 (A, B and C rings) carbon skeleton, exhibit several patterns of hydroxylation, acylation, glycosylation and methoxylation of the main structure 
of each phenolic compound. ${ }^{9}$ Also, these substituents may be found in phenolic acid derivatives and polymers, and may explain their biological importance, which is seriously compromised during digestion. ${ }^{9,11-13}$

In blackberry fruits, polyphenols are the main compounds responsible for fruit sensory properties, and their stability is highly dependent on factors such as light exposure, $\mathrm{pH}$, native chemical structure, sugar conjugation, temperature, metal ions, oxygen, and enzymes. ${ }^{14,15}$ Phenolic compounds are stored in cell structures (e.g. vacuoles and cell walls) of the skin, pulp and seeds of fruits. ${ }^{15}$ These compounds are bound to macromolecules, such as proteins and peptides (linking the phenolic group of the phenol ring with the - $\mathrm{NH}$ group of peptides) or carbohydrates (liked by $\alpha$ - and $\beta$-glycosidic bonds), the dry matter content of which is about $80 \%$ and $5 \%$, respectively. ${ }^{8,16}$ It should be noted, however, that these macromolecules undergo marked degradation during GID, becoming bioavailable sugars and small peptides/amino acids. ${ }^{17}$

With increasing evidence that supports the bioactive effects of multiple phenolic compounds present in foods, there is a need to develop methods for simulating the physiological conditions, with harmonized requirements and predictable outcomes of in vivo GID experiments using non-invasive procedures. ${ }^{17}$ Recent data suggest that the transformation of phenolic compounds during GID stages is attributable to several factors, such as $\mathrm{pH}$ changes, enzyme activity and concentration, peristaltic movements, and food matrices. ${ }^{9,17-19}$

Several protocols have been used to study the bioaccessibility of phenolic compounds in red fruits. ${ }^{6,11,20,21}$ To date, however, no clear consensus has been reached on the biotransformation of these phytochemicals. It is crucial to acquire more knowledge in this regard to be able to determine the bioaccessibility and bioactivity of berry phenolics, since we still do not have a clear picture of the mechanisms involved prior to transport through the small intestine epithelium into the bloodstream., ${ }^{9,18}$ Keeping in mind the above considerations, it is necessary to prevent extra degradation of phenolics by external factors (due to atmospheric $\mathrm{O}_{2}$ and/or the presence of light) during in vitro GID protocols. ${ }^{11,17}$ Therefore, the objectives of the present study were (a) to evaluate the bioaccessibility and digestive stability of each phenolic compound after GID, using the INFOGEST® 2.0 protocol; (b) to determine the in vitro antioxidant activity of wild (WB) and commercial (CB) blackberry polyphenols during GID; and (c) to assess the antioxidant potential of WB and CB digestates based on their cellular antioxidant activity (CAA) and their capacity to inhibit the synthesis of reactive oxygen species (ROS) in the Caco-2 cell line.

\section{Materials and methods}

\subsection{Biological material and reagents}

Ripe wild blackberry (Rubus liebmannii Focke) fruits (WB) were collected in El Palmito, Sinaloa, Mexico $\left(23^{\circ} 35^{\prime} 22.2^{\prime \prime} \mathrm{N}, 105^{\circ} 52^{\prime}\right.$ $11.8^{\prime \prime} \mathrm{W}, 2170 \mathrm{mASL}$ ), at the beginning of summer 2018, while commercial Rubus fruticosus brambles (CB) were purchased at a local market. WB and $\mathrm{CB}$ fruits were weighed, frozen at $-80{ }^{\circ} \mathrm{C}$, and then freeze-dried (FreeZone Dryer System; Labconco, Kansas City, MO, USA) and weighed again. All reagents and enzymes were obtained from Sigma-Aldrich, unless otherwise stated. Commercial standards of cyanidin-3rutinoside (PHL80577), gallic acid (G7384), chlorogenic acid (C38378), catechin (C1788), vanillic acid (94770), caffeic acid (C0625), epicatechin (E1753), p-coumaric acid (C9008), ferulic acid (Y0001013), quercetin (Q4951), and kaempferol (60010) were used for phenolic identification and/or AOX evaluation. Reagents 2,2'-azino-bis(3-ethylbenzothiazoline-6-sulphonic acid) (ABTS, A9941), di(phenyl)(2,4,6-trinitrophenyl)iminoazanium (DPPH, D9132), $\beta$-carotene (C9750), 2,2'-azobis(2-amidinopropane)dihydrochloride (AAPH, 440914), potassium persulphate $\left(\mathrm{K}_{2} \mathrm{~S}_{2} \mathrm{O}_{8}, 216224\right)$, Tween-20 (P7950), linolenic acid (L2376), potassium hexacyanoferrate(III) $\left(\mathrm{K}_{3} \mathrm{Fe}(\mathrm{CN})_{6}, \mathrm{P} 8131\right)$, iron(III) chloride hexahydrate $\left(\mathrm{FeCl}_{3}, 236489\right)$, sodium bicarbonate $\left(\mathrm{NaHCO}_{3}, \mathrm{S6297}\right)$, fluorescein (F46960), and FolinCiocalteu's reagent (F9252) were used. Calcium chloride $\left(\mathrm{CaCl}_{2}, 449709\right)$ and $\alpha$-amylase enzymes from porcine pancreas (EC 3.2.1.1, A3176), pepsin from porcine gastric mucosa (EC 3.24.3.1, P7012), trypsin from bovine pancreas (EC 3.4.21.1, T0303), $\alpha$-chymotrypsin from bovine pancreas (EC 3.4.21.1, C4129), lipase from porcine pancreas Type II (EC 3.1.1.3, L3126), and bile salt from porcine bile extract (B8631) were used. Butylated hydroxytoluene (BHT, W218405), Trolox (238813), and cyanidin-3-glucoside chloride (89616 PhytoLab $\mathrm{GmbH}$ \& Co. KG, Vestenbergsgreuth, Germany) were utilized as external standards in different experiments. For cellular experiments, Gibco Thermo Fisher Scientific (Life Technologies Corp., San Diego, CA, USA) supplied Dulbecco's modified Eagle's medium (DMEM, 11965-092) and Hank's balanced salt solution (HBSS, 14025-092), while fetal bovine serum (FBS, 080450), non-essential amino acids (321-011-EL), L-glutamine (609-065-EL), penicillin-streptomycin (450-201EL), Dulbecco's phosphate-buffered saline (DPBS, 311-425-CL), dichlorofluorescein diacetate (DCFH-DA, D6883) and Hepes (330-050-EL) were provided by Wisent Bioproducts (Wisent Inc., Saint-Jean-Baptiste, QC, Canada). Hydrogen peroxide (H1009) also was required. Sodium hydroxide $(\mathrm{NaOH})$ and hydrochloric acid $(\mathrm{HCl})$ were used at different concentrations to adjust the $\mathrm{pH}$.

\subsection{Simulated in vitro gastrointestinal digestion}

In vitro gastrointestinal digestion (GID) was performed following the INFOGEST ${ }^{\circledR} 2.0$ protocol, ${ }^{17}$ incorporating specific conditions for the digestion of phenolic compounds, as described by Gil-Izquierdo et $a .^{20}$ and Bermúdez-Soto et $a{ }^{11}{ }^{11}$ Briefly, $20 \mathrm{~g}$ of rehydrated WB and CB fruits (with original water proportions) were placed in a $250 \mathrm{~mL}$ amber screw cap bottle and homogenized with an Ultra-Turrax® (IKA, Germany) for $30 \mathrm{~s}$. To mimic the oral phase (OP), samples were mixed with simulated salivary fluid $(1: 1, \mathrm{w} / \mathrm{v})$ and adjusted to $\mathrm{pH} 7.0$ with $4 \mathrm{~N}$ $\mathrm{NaOH}, 100 \mu \mathrm{L}$ of $0.3 \mathrm{M} \mathrm{CaCl}_{2}$, and $1500 \mathrm{U} \mathrm{mL}^{-1}$ of $\alpha$-amylase. The mixture was stirred for $2 \mathrm{~min}$ at $350 \mathrm{rpm}$ on a StableTemp stirring-hot plate at $37^{\circ} \mathrm{C}$ (Cole-Palmer Instruments Company, 
IL, USA). An aliquot of $5 \mathrm{~mL}$ was recovered at the end of the OP. After that, the bolus $(35 \mathrm{~mL})$ was mixed with simulated gastric fluid (SGF) $(1: 1, \mathrm{v} / \mathrm{v})$, the $\mathrm{pH}$ was adjusted to 3.0 with $1 \mathrm{~N} \mathrm{HCl}$ and $17.5 \mu \mathrm{L}$ of $0.3 \mathrm{M} \mathrm{CaCl}_{2}$, and $2500 \mathrm{U} \mathrm{mL}^{-1}$ of pepsin were added. Gastric phase (GP) digestion was carried out for $2 \mathrm{~h}$ under constant shaking (100 rpm) at $37^{\circ} \mathrm{C}$ using an Innova ${ }^{\circledR} 40$ incubator (Incubator Shaker Series, New Brunswick Scientific, NJ, USA). The intestinal phase (IP) started with the resulting volume $(50 \mathrm{~mL})$, which was mixed with an equal volume of simulated intestine fluid (SIF); the $\mathrm{pH}$ was adjusted to 7.0 and then $100 \mu \mathrm{L}$ of $0.3 \mathrm{M} \mathrm{CaCl}_{2}$, trypsin (100 $\left.\mathrm{U} \mathrm{mL}^{-1}\right), \alpha$-chymotrypsin $\left(25 \mathrm{U} \mathrm{mL}^{-1}\right)$, lipase (2000 U $\mathrm{mg}^{-1}$ of fat), $\alpha$-amylase $\left(200 \mathrm{U} \mathrm{mL}^{-1}\right)$, and bile salt $(10 \mathrm{mM}$ $\left.\mathrm{mL}^{-1} \mathrm{SIF}\right)$ were added. An anaerobic atmosphere was maintained with $\mathrm{N}_{2}$ flushing during the addition of SGF and SIF, as well as during aliquot sampling every $30 \mathrm{~min}$. Aliquots of $5 \mathrm{~mL}$ were recovered every 30 min during the GP and IP phases. Digestates were mixed with pure methanol $(1: 1, \mathrm{v} / \mathrm{v})$ to precipitate enzymes. Then samples were centrifuged at $10000 \mathrm{~g}$ for $5 \mathrm{~min}$ at $4{ }^{\circ} \mathrm{C}$. Supernatants were filtered with a $0.45 \mu \mathrm{L}$ nylon filter, freeze-dried and stored in light-protected tubes at $-80{ }^{\circ} \mathrm{C}$ for further use.

\subsection{Total phenolic and anthocyanin content}

To assess the total phenolic content (TPC) of various samples, $50 \mu \mathrm{L}$ of resuspended fruit extracts and digested samples (1:50, fruit extract or digestate: distilled water, w/v) were mixed with $100 \mu \mathrm{L}$ of $70 \%$ acetone-1\% $\mathrm{HCl}$ solution (acetone/ water $/ \mathrm{HCl}(70: 29: 1, \mathrm{v} / \mathrm{v} / \mathrm{v})$ and maintained at room temperature for $2 \mathrm{~h}^{22}$ After the $2 \mathrm{~h}$ period, $100 \mu \mathrm{L}$ of standard solution (gallic acid $0-500 \mu \mathrm{g} \mathrm{mL} \mathrm{m}^{-1}$ ) or $100 \mu \mathrm{L}$ of the mixture were suspended in $750 \mu \mathrm{L}$ of Folin-Ciocalteu solution $(1: 10$, FolinCiocalteu's reagent:water), vortexed and left to stand for 5 min. Then, $750 \mu \mathrm{L}$ of $\mathrm{NaHCO}_{3}$ solution (7.5\%) was added to the above solution, which was vortexed and centrifuged at $10000 \mathrm{~g}$ for 15 min (Benchmark Z206-A Centrifuge, Beckman Coulter, Indianapolis, IN, USA). Finally, $250 \mu \mathrm{L}$ of each of the aforementioned mixtures were retained in the dark at room temperature, and were read at $750 \mathrm{~nm}$ on a microplate reader (BioTek Instruments, VT, USA) equipped with Gen5 software version 3.02 (BioTek Instruments, VT, USA). The results were expressed as $\mu \mathrm{g}$ of gallic acid equivalents (GAE) per $\mathrm{mL}$.

The differential $\mathrm{pH}$ method was applied to determine the total anthocyanin content (TAC). ${ }^{23}$ Briefly, the $\mathrm{pH}$ of $100 \mu \mathrm{L}$ of WB or CB was adjusted to 1.0 with $1 \mathrm{~N} \mathrm{HCl}$, or to 4.5 with $1 \mathrm{~N}$ $\mathrm{NaOH}$. Aliquots were measured at $520 \mathrm{~nm}$ and $700 \mathrm{~nm}$ using a microplate reader (BioTek Instruments, VT, USA) equipped with Gen5 software version 3.02 (BioTek Instruments, VT, USA).

\subsection{Characterization of the phenolic compounds}

Freeze-dried fruits and digestates of WB and CB (100 mg) were resuspended in water: $\mathrm{MeOH}(50: 50, \mathrm{v} / \mathrm{v})$, centrifuged at 15000 rpm (Z206-A Centrifuge, Beckman Coulter, Indianapolis, IN, USA) and analyzed with the procedure reported by Jiao et $a .^{12}$ and Iglesias-Carres et al. $^{24}$ using a
1290 UHPLC Infinity II series instrument coupled to a qTOF/ MS 6550 system (Agilent Technologies, Palo Alto, CA, USA). Two different methodologies based on UHPLC-ESI-qTOF-MS systems were used to separate, detect, and quantify the nonanthocyanin and anthocyanin phenolic compounds. For the separation of non-anthocyanin compounds, an Acquity HSST3 C18-column $(150 \times 2.1 \mathrm{~mm}, 1.8 \mu \mathrm{m}$ particle size) (Waters, Milford, MA, USA) was used. The mobile phase consisted of (A) water : acetic acid (99.8:0.2, v/v) and (B) acetonitrile. The gradient mode was as follows: 0-0.5 $\mathrm{min}, 0 \% \mathrm{~B} ; 0.5-18 \mathrm{~min}$, 0-30\% B; 18-21 $\min , 30-95 \% \mathrm{~B} ; 21-24 \mathrm{~min}, 95 \% \mathrm{~B}$; and 24-25 $\mathrm{min}, 100-0 \% \mathrm{~B}$. A post-run time of $6 \mathrm{~min}$ was required for column re-equilibration (at $0 \% \mathrm{~B}$ ). The flow rate was set at $0.55 \mathrm{~mL} \mathrm{~min}^{-1}$ and column temperature at $45^{\circ} \mathrm{C}$; the injection volume was $2.5 \mu \mathrm{L}$ for all runs. Electrospray ionization (ESI) operating in negative mode was conducted with a gas temperature at $200{ }^{\circ} \mathrm{C}$ and a flow rate of $14 \mathrm{~L} \mathrm{~min}^{-1}$. A nebulizer gas pressure of $20 \mathrm{psi}$, sheath gas temperature of $350{ }^{\circ} \mathrm{C}$, sheath gas flow of $11 \mathrm{~L} \mathrm{~min}^{-1}$ and capillary voltage of $3000 \mathrm{~V}$ were used. The anthocyanin compounds were separated on an Acquity BEH C18 column $(100 \mathrm{~mm} \times 2.1 \mathrm{~mm}, 1.7 \mu \mathrm{m}$ particle size) (Waters) and the mobile phase consisted of water : formic acid $(9: 1, \mathrm{v} / \mathrm{v})(\mathrm{A})$ and acetonitrile (B). The gradient mode was as follows: $0-0.5 \mathrm{~min}, 0 \% \mathrm{~B}$; 0.5-5 $\mathrm{min}, 0-9 \% \mathrm{~B}$; 5-7 $\mathrm{min}$, 9-15\% B; 7-9.5 min, 15-30\% B; 9.5-10 $\mathrm{min}, 30-100 \% \mathrm{~B}$; 10-12 $\mathrm{min}, 100 \% \mathrm{~B}$; and $12-12.1 \mathrm{~min}, 100-0 \% \mathrm{~B}$. A post-run time of $5 \mathrm{~min}$ was required for column re-equilibration (at $0 \%$ B). The flow rate was set at $0.4 \mathrm{~mL} \mathrm{~min}^{-1}$ and column temperature at $25{ }^{\circ} \mathrm{C}$, and the injection volume was $2.5 \mu \mathrm{L}$ for all runs. ESI operating in positive mode was conducted with a gas temperature of $200{ }^{\circ} \mathrm{C}$ and the flow rate was $14 \mathrm{~L} \mathrm{~min}^{-1}$. A nebulizer gas pressure of $20 \mathrm{psi}$, sheath gas temperature of $350{ }^{\circ} \mathrm{C}$, sheath gas flow of $11 \mathrm{~L} \mathrm{~min}^{-1}$ and capillary voltage of $3000 \mathrm{~V}$ were used. The mass spectra were recorded between $\mathrm{m} / \mathrm{z} 100$ and 1000 at 2.5 spectra per $s$ for both methodologies.

Identification of the phenolic compounds was performed by direct comparison with commercial standards or by comparison with the molecular weight for phenolic compounds in the Phenol-Explorer database (http://www.phenol-explorer.eu) on the basis of chromatographic behavior, ion molecular mass $\left([\mathrm{M}-\mathrm{H}]^{-}\right.$or $\left.[\mathrm{M}]^{+}\right)$and fragmentation patterns. The calibration curves from commercial standards were used to quantify the corresponding phenolic compounds. For the other compounds, the analysis was semi-quantitative. The behavior of each compound was evaluated, and the calibration curve chosen to calculate its concentration was that of the phenolic compound exhibiting the most similar behavior. ${ }^{24}$

\subsection{Bioaccessibility of WB and CB phenolic compounds}

The bioaccessibility index (BI) of each phenolic compound was calculated using the following equation:

$$
\mathrm{BI}=\frac{\mathrm{IC}}{\mathrm{FC}} \times 100
$$

where IC is the initial concentration of phenolics (concentration in the fruits before GID) and FC is the final concen- 
tration of phenolics (concentration in the digestate of the intestinal phase at $120 \mathrm{~min}) .^{25}$

\subsection{Antioxidant activity}

The antioxidant activity (AOX) of phenolics is one of the most relevant properties of these compounds. ${ }^{4,12,26,27}$ The AOX of polyphenols largely depends on the number and position of the hydroxyl groups on the flavylium cation, which gives them their hydrogen-donating capacity. Hydrogen atom transfer (HAT) is one of the mechanisms involved; single electron transfer (SET) ability is another mechanism by which polyphenols stabilize/scavenge free radicals. ${ }^{28}$ In addition, single-electron transfer followed by proton transfer (SET-PT) has recently been studied. ${ }^{29}$ Accordingly, it is necessary to evaluate the evolution of the berries' phenolics during digestion to determine the possible antioxidant mechanisms of action and their fate during GID. All undigested and digested aliquots of WB and $\mathrm{CB}$ were normalized at $100 \mathrm{mg}$ GAE per $\mathrm{mL}$ of sample before in vitro AOX assessment.

2.6.1 Oxygen radical antioxidant capacity (ORAC). The ORAC assay was performed following the procedure reported by Ou et al. ${ }^{30}$ The declining fluorescein $(0.1 \mu \mathrm{M})$ absorbance by AAPH $\cdot(153 \mathrm{mM})$ at $37{ }^{\circ} \mathrm{C}$ was recorded at 1 min intervals for $60 \mathrm{~min}$ at $485 / 528 \mathrm{~nm}$ of excitation/emission using a Synergy HT multi-detection microplate reader (BioTek Instruments, Inc., Winooski, VT, USA). PBS buffer ( $\mathrm{pH}$ 7.4) was used to dissolve samples at $100 \mu \mathrm{g} \mathrm{mL}^{-1}$ and along with Trolox standard (0-100 $\left.\mu \mathrm{M} \mathrm{mL}^{-1}\right)$. The antioxidant capacity (AOX) was estimated using Trolox as the standard curve and the following equation:

$$
\mathrm{AOX}=\left[\frac{\mathrm{AUC}_{\text {sample }}-\mathrm{AUC}_{\text {blank }}}{\mathrm{AUC}_{\text {Trolox }}-\mathrm{AUC}_{\text {blank }}}\right] \times k
$$

where $\mathrm{AUC}_{\text {sample }}$ is the integrated area under the fluorescence decay curve of each sample solution, $\mathrm{AUC}_{\mathrm{blank}}$ is the integrated area under the fluorescence decay curve of the blank, $\mathrm{AUC}_{\text {Trolox }}$ is the integrated area under the Trolox fluorescence decay standard curve, and $k$ is the dilution factor. Results were expressed as $\mu \mathrm{M}$ of Trolox equivalent (TE) per $\mathrm{mL}$ of sample.

2.6.2 DPPH radical-scavenging activity. The DPPH radicalscavenging activity was determined according to the method of Sánchez-Vioque et al. ${ }^{31}$ Trolox standard and normalized samples were mixed at a $1: 1(\mathrm{v} / \mathrm{v})$ ratio with freshly prepared $0.1 \mathrm{mM}$ DPPH. The microplate was incubated in the dark under agitation (New Brunswick ${ }^{\mathrm{TM}}$ Innova ${ }^{\circledR}$ 40/40R Incubator Shaker, Eppendorf, Inc. USA) at room temperature for $30 \mathrm{~min}$. Absorbance was measured at $517 \mathrm{~nm}$ on a microplate reader and $\mathrm{AOX}$ was calculated using the following equation:

$$
\mathrm{RI}(\%)=\left[\frac{\mathrm{ABS}_{\text {sample }}-\mathrm{ABS}_{\text {blank }}}{\mathrm{ABS}_{\text {Trolox }}-\mathrm{ABS}_{\text {blank }}}\right] \times k
$$

where $\mathrm{RI}$ is the radical inhibition, $\mathrm{ABS}_{\text {sample }}$ is the absorbance of the samples, $\mathrm{ABS}_{\text {blank }}$ is the absorbance of the blank, $\mathrm{ABS}_{\text {Trolox }}$ is the absorbance of the Trolox standard, and $k$ is the dilution factor. Results were expressed as percentage of DPPH radical inhibition (\%).
2.6.3 Trolox equivalent antioxidant capacity (TEAC). The Trolox equivalent antioxidant capacity (TEAC) of samples based on the scavenging of $\mathrm{ABTS}^{\circ+}$ was measured following the method of Re et al. ${ }^{32}$ A solution of $7 \mathrm{mM}$ ABTS reagent was prepared with $40 \mathrm{mg}$ of ABTS salt and $6.95 \mathrm{mg}$ of $2.45 \mathrm{mM} \mathrm{K} \mathrm{S}_{2} \mathrm{O}_{8}$ solution, which was adjusted to $10 \mathrm{~mL}$ with distilled water and maintained in the dark for $16 \mathrm{~h}$ at room temperature. The ABTS reagent solution was then diluted with EtOH to obtain an absorbance of $0.80 \pm 0.1$ at $734 \mathrm{~nm}$. Blank, standards and normalized samples were mixed with ABTS solution $(1: 10, \mathrm{v} / \mathrm{v})$ and vortexed for $10 \mathrm{~s}$, then the absorbance was read at 0 and $6 \mathrm{~min}$ at $734 \mathrm{~nm}$. A Trolox curve $(0-0.7 \mathrm{mM})$ was used. AOX was calculated using the following equation:

$$
\mathrm{RI}(\%)=\left[\frac{\mathrm{ABS}_{\text {sample }}-\mathrm{ABS}_{\text {blank }}}{\mathrm{ABS}_{\text {Trolox }}-\mathrm{ABS}_{\text {blank }}}\right] \times k
$$

where $\mathrm{RI}$ is the radical inhibition, $\mathrm{ABS}_{\text {sample }}$ is the absorbance of the samples, $\mathrm{ABS}_{\mathrm{blank}}$ is the absorbance of the blank, $\mathrm{ABS}_{\text {Trolox }}$ is the absorbance of the Trolox standard, and $k$ is the dilution factor. Results were expressed as a percentage of ABTS radical inhibition (\%).

2.6.4 $\beta$-Carotene bleaching activity. The antioxidant activity assay measuring $\beta$-carotene discoloration was used as described by Marco et al. $^{33}$ A solution of $1 \mathrm{mg} \mathrm{mL}^{-1}$ of $\beta$-carotene reagent diluted in chloroform and mixed with $200 \mu \mathrm{L}$ of Tween-20 and $20 \mu \mathrm{g}$ of linolenic acid was prepared. The resulting mixture was diluted with $20 \mathrm{~mL}$ of water previously flushed with $\mathrm{O}_{2}$ (stock solution). An aliquot of this stock solution was diluted with oxygen-rich water to obtain a $\beta$-carotene working solution (absorbance of 1.2-1.3 at $450 \mathrm{~nm}$ ). The working solution was maintained in an ice bath in the dark before being used. Then $50 \mu \mathrm{L}$ of normalized samples or blank were mixed with $200 \mu \mathrm{L}$ of working solution and incubated under agitation at $37{ }^{\circ} \mathrm{C}$, and the absorbance was measured at 0 and $60 \mathrm{~min}$ at $450 \mathrm{~nm}$. The following equation was used to calculate the antioxidant activity:

$$
\mathrm{DR}=\frac{\operatorname{Ln} \frac{\mathrm{ABS}_{0 \mathrm{~min}}}{\mathrm{ABS}_{60 \mathrm{~min}}}}{60}
$$

where $\mathrm{DR}$ is the degradation rate for the absorbance at the beginning $\left(\mathrm{ABS}_{0} \mathrm{~min}\right)$ and the end of the reaction $\left(\mathrm{ABS}_{60} \mathrm{~min}\right)$ for the control and samples. Using the DR, AOX was calculated as a percentage of $\beta$-carotene relative inhibition against the blank:

$$
\operatorname{AOX}(\%)=\left[\frac{\mathrm{DR}_{\text {blank }}-\mathrm{DR}_{\text {sample }}}{\mathrm{DR}_{\text {blank }}}\right] \times 100
$$

where $\mathrm{DR}_{\text {blank }}$ indicates the degradation of $\beta$-carotene in the absence of sample. Results were expressed as percentage of $\beta$-carotene bleaching inhibition (\%).

2.6.5 Reducing power. The reducing power assay was performed according to the method of Carrasco-Castilla et al. ${ }^{34}$ Briefly, $50 \mu \mathrm{L}$ of normalized sample were mixed with $50 \mu \mathrm{L}$ of $0.2 \mathrm{M}$ phosphate buffer ( $\mathrm{pH}$ 6.6) and $50 \mu \mathrm{L}$ of fresh (prepared daily) $1 \% \mathrm{~K}_{3} \mathrm{Fe}(\mathrm{CN})_{6}$ solution. The microplate containing the 
resulting samples was incubated for $20 \mathrm{~min}$ at $50{ }^{\circ} \mathrm{C}$ under agitation at $100 \mathrm{rpm}$ (New Brunswick ${ }^{\mathrm{TM}}$ Innova ${ }^{\circledR}$ 40/40R Incubator Shaker, Eppendorf, Inc. USA). After that, $50 \mu \mathrm{L}$ of $10 \%$ TCA and $10 \mu \mathrm{L}$ of $0.1 \% \mathrm{FeCl}_{3}$ were added to each well and the incubation was continued for an additional $10 \mathrm{~min}$ at $50{ }^{\circ} \mathrm{C}$ under agitation. The absorbance was read at $700 \mathrm{~nm}$ and compared with a BHT curve $\left(0.0-0.05 \mu \mathrm{g} \mu \mathrm{L}^{-1}\right)$. Results were expressed as the absorbance (Abs) at $700 \mathrm{~nm}$.

\subsection{Cellular bioactivity}

2.7.1 Caco-2 cell culture. Caco- 2 cells were obtained from the American Type Culture Collection (ATCC® HTB-37 ${ }^{\mathrm{TM}}$, Manassas, VA, USA) and were cultivated in DMEM (supplemented with 10\% FBS, 1\% non-essential amino acids, 1\% L-glutamine, and $1 \%$ penicillin-streptomycin). The cells were grown in a $75 \mathrm{~cm}^{2}$ flask under a humidified atmosphere $(5 \%$ $\mathrm{CO}_{2}$ ) at $37{ }^{\circ} \mathrm{C}$ until $80 \%$ confluence was reached. ${ }^{35}$ Cells were sub-cultured twice a week. Trypan blue dye was used to assess cellular viability.

2.7.2 Caco-2 cytotoxicity assay. Caco- 2 cells were seeded in a 96-well flat-bottomed plate (passage number 31), at a concentration of $2.2 \times 10^{4}$ cells per well in $100 \mu \mathrm{L}$ of DMDM. Following $24 \mathrm{~h}$ of incubation (Series 8000DH $\mathrm{CO}_{2}$ incubator, Thermo Fisher Scientific, Marietta, OH, USA), the samples of a specific concentration (0.1-1000 $\mu \mathrm{g}$ GAE per $\mu \mathrm{L})$ were added and incubation was continued for an additional $24 \mathrm{~h}$. After that, the 3-(4,5-dimethylthiazol-2-yl)-2,5-diphenyltetrazolium bromide (MTT) assay was performed by following the MTT kit's instructions (M2128 Millipore Sigma, Burlington, MA, USA). The culture medium was removed and replaced with fresh medium $(100 \mu \mathrm{L})$ to the blank (without sample) and sample wells, and MTT solution $(10 \mu \mathrm{L})$ was added to each well. After an additional incubation step for $4 \mathrm{~h}$ in the dark, the MTT formazan produced in wells containing live cells appeared as black, fuzzy crystals on the bottom of the well. Then, $100 \mu \mathrm{L}$ of isopropanol with $0.04 \mathrm{~N} \mathrm{HCl}$ was added to the wells and agitated $(30 \mathrm{~s}, 100 \mathrm{rpm}$ at room temperature and in darkness). Finally, within the next hour, the plate was read at $570 / 630 \mathrm{~nm}$ against a blank. The metabolic activity (\% MA) of the cells was calculated using the following equation:

$$
\% \mathrm{MA}=\left[\frac{A_{\text {digestate }}}{A_{\text {control }}}\right] \times 100
$$

where $A_{\text {digestate }}$ is the absorbance of the sample exposed to the extract and $A_{\text {control }}$ is the absorbance of the control sample (cells without extract exposition, 100\% metabolic activity). The results were expressed as the half-maximal effective concentration $\left(\mathrm{EC}_{50}\right)$ in $\mathrm{mg}$ of phenolic compounds per $\mathrm{mL}$ of sample $\left(\mathrm{mg} \mathrm{mL}^{-1}\right)$.

2.7.3 Cellular antioxidant activity. The cellular antioxidant activity (CAA) of digested samples was measured according to the method of Kellett et al. ${ }^{35}$ After Caco- 2 cells reached confluence ( $80 \%$ confluence), cells were seeded at a density of $6 \times 10^{5}$ cells per $\mathrm{mL}$ (passage number 32) in a 96-well black clearbottomed microplate and incubated until confluence (24-48 h) under the conditions described in the previous section.
Confluence was confirmed using the microscope. The outside wells of the plate were not used. Prior to the experiment with digestates, growth medium was removed and cell monolayers were washed twice with DPBS. Then, $50 \mu \mathrm{L}$ of treatment medium (FBS free medium) and $25 \mu \mathrm{M}$ DCFH-DA working solution were added to each well along with $50 \mu \mathrm{L}$ of the samples $(100 \mu \mathrm{g}$ GAE per $\mathrm{mL})$. Once the DCFH-DA and blackberry samples were added, the cells were placed in the incubator for $1 \mathrm{~h}$ at $37^{\circ} \mathrm{C}$. When only intracellular CAA was being measured, wells were washed three times with $100 \mu \mathrm{L}$ of DPBS. Then, the AAPH radical solution $(100 \mu \mathrm{L}, 600 \mu \mathrm{M}$ AAPH in HBSS) was added to each well. The cells were immediately placed in a microplate reader (BMGLABTECH Inc., Cary, NC, USA), where real-time fluorescence was read at an excitation wavelength of $485 \mathrm{~nm}$ and an emission wavelength of $538 \mathrm{~nm}$ every minute for $1 \mathrm{~h}$. For the control, $50 \mu \mathrm{L}$ of DCFH-DA and $50 \mu \mathrm{L}$ of serum-free culture medium (no samples included) were added to the wells in triplicate. A standard curve with quercetin $(0-250 \mu \mathrm{M})$ was used. All samples were analyzed in triplicate. For CAA quantification, first, the blank subtraction (wells without samples) was done, followed by integration of the area under the curve of fluorescence $v s$. time at each concentration of sample, as follows:

$$
\mathrm{CAA}(\%)=100-\left[\int \mathrm{SA} / \int \mathrm{CA}\right] \times 100
$$

where $\int \mathrm{SA}$ is the integrated area under the sample fluorescence $v s$. time curve and $\int \mathrm{CA}$ is the integrated area from the curve. Results were expressed as fluorescence inhibition compared with the quercetin curve standard (\%).

2.7.4 Cellular oxidative stress. Oxidative stress in Caco-2 cells was evaluated under the DCFH-DA assay conditions, ${ }^{36}$ with some modifications. When cells reached $80 \%$ confluence, the Caco- 2 cell line was grown at a density of $2 \times 10^{4}$ cells per well (passage number 33) in a black flat-bottomed 96-well microplate for $24 \mathrm{~h}-48 \mathrm{~h}$ under optimal conditions until confluence was reached (confirmed using a microscope). The outside wells of the plate were not used. Prior to the experiment, growth medium was removed and cell monolayers were washed twice with $100 \mu \mathrm{L}$ of DPBS, then cells were incubated for 30 min with $100 \mu \mathrm{M}$ DCFH-DA and with sample, both diluted in HBSS. The wells were then washed with fresh DPBS solution before $100 \mu \mathrm{M}$ of $\mathrm{H}_{2} \mathrm{O}_{2}$ was added. The fluorescence increase ratio (FIR) was evaluated at 0 and $30 \mathrm{~min}$ (ex/em: 485/ $530 \mathrm{~nm}$ ) on a microplate reader (BMGLABTECH Inc., Cary, NC, USA). The positive control wells contained the cells treated with DCFH-DA and $\mathrm{H}_{2} \mathrm{O}_{2}$. For the negative control wells, $100 \mu \mathrm{L}$ of HBSS without $\mathrm{H}_{2} \mathrm{O}_{2}$ was added to the blank wells. FIR was calculated as:

$$
\mathrm{FIR}=\left[\frac{F_{30 \mathrm{~min}}-F_{0 \mathrm{~min}}}{F_{0 \mathrm{~min}}}\right] \times 100
$$

where $F_{0}$ min is the fluorescence value at $0 \mathrm{~min}$ and $F_{30} \min$ is the fluorescence at $30 \mathrm{~min}$. FIR was expressed as the percentage (\%) of the positive control. 


\subsection{Statistical analysis}

Data were expressed as means \pm SD. Statistical differences were analyzed using the one-way analysis of variance (ANOVA) under Tuckey's test, with Minitab 2013 (Minitab Inc., USA). The differences were considered to be statistically significant at $p<$ 0.05 .

\section{Results and discussion}

\subsection{In vitro GID}

Ten aliquots of each blackberry genotype were recovered at different stages during GID: one aliquot for undigested fruit; one aliquot after OP (2 min); 4 aliquots for GP (30, 60, 90 and $120 \mathrm{~min}$ ); and 4 aliquots for IP (30, 60, 90 and $120 \mathrm{~min})$. In most of the published studies on GID of red fruits, ${ }^{13,21,37-41}$ the digestive procedure was performed in two phases (GP and IP), excluding the first digestive stage (OP). The oral phase is of special importance during the digestion process, since it is during this phase that the plant matrix containing phytocompounds is broken down during the chewing step, the components are exposed to the salivary fluids and to the action of $\alpha$-amylase, and an anaerobic atmosphere begins. Sigurdson and Giusti ${ }^{9}$ and Brodkorb et al. ${ }^{17}$ have highlighted the key role that the OP plays in the simulation of gastrointestinal digestion for food matrices with a high carbohydrate content $(>80 \%$ of dry matter) and in the possible absorption of nutrients that occurs in the oral epithelium.

\subsection{Effect of GID on TPC and TAC}

The total phenolic content (TPC) of undigested and digested fruits of WB and $\mathrm{CB}$ is shown in Fig. 1A. For undigested fruits of $\mathrm{WB}$ and $\mathrm{CB}$, the TPC was 127 and $79 \mathrm{mg}$ EAG per $\mathrm{mL}$, respectively, with the TPC being significantly higher for WB $(p<0.05)$ than for CB. Following the OP $(2 \mathrm{~min})$, the TPC of WB decreased to $53 \mathrm{mg}$ EAG per $\mathrm{mL}$, which was $58 \%$ lower than for the corresponding undigested sample, while the $\mathrm{CB}$ sample showed a TPC of $54 \mathrm{mg}$ EAG per mL, which represented a decrease of $31 \%$ relative to the undigested sample. There was no significant difference $(p>0.05)$ in the TPC between the two types of blackberries following the OP. For $\mathrm{GP}_{30}$ min, the WB digestates showed values of $44 \mathrm{mg}$ EAG per $\mathrm{mL}$, with no significant difference $(p>0.05)$ when compared to the corresponding $\mathrm{GP}_{60}$ min digestates (42 $\mathrm{mg}$ EAG per $\mathrm{mL}$ ). Digestates obtained after 90 min of GP $\left(\mathrm{GP}_{90} \mathrm{~min}\right)$ had a TPC of $40 \mathrm{mg}$ EAG per $\mathrm{mL}$, which was not significantly $(p>0.05)$ different from the value observed after $30 \mathrm{~min}$ or after $60 \mathrm{~min}$. For the same stage, the TPC of CB was 49-52 mg EAG per mL, with no significant difference $(p>0.05)$ between $\mathrm{GP}_{30} \mathrm{~min}$, $\mathrm{GP}_{60}$ min and $\mathrm{GP}_{90}$ min. However, these values were statistically higher $(p<0.05)$ than the ones reported for the corresponding WB. During the IP, the TPC of WB showed values of $37-38 \mathrm{mg}$ EAG per $\mathrm{mL}$, with no statistical differences $(p>0.05)$ between $\mathrm{IP}_{30 \mathrm{~min}}, \mathrm{IP}_{60 \mathrm{~min}}, \mathrm{IP}_{90 \text { min }}$ and $\mathrm{IP}_{120 \mathrm{~min}}$, while the TPC of the CB digestates varied between 25 and $31 \mathrm{mg}$ EAG per $\mathrm{mL}$, with no significant differences $(p>0.05)$ between them; however, the TPC values were lower $(p<0.05)$ than those for the WB digestates. These changes in TPC represent a decrease of $70 \%$ in $\mathrm{WB}$ and $68.35 \%$ in $\mathrm{CB}$. This indicates that the phenolic compounds of digested WB are slightly less stable than those found in digested CB.

The quantification of phenolic compounds in the fruits and digestates of blackberries is of great importance, since they are the main group of secondary metabolites in these fruits and they display multiple benefits for human health. ${ }^{9,42}$ Phenolic compounds are released from the plant matrix (mainly from cellular carbohydrates with structural functions) through enzymatic action and $\mathrm{pH}$ oscillations during the different digestive stages; ${ }^{43-45}$ however, these compounds are not always stable during and after GID. The TPC of Rubus fruit digestates showed a decrease of $>41 \%$ in commercial raspberry ${ }^{45}$ and $>72 \%$ in blackberry ${ }^{46}$ following GID. However, in R. hirsutus, Chen et al. ${ }^{39}$ found an increase of $26 \%$ in TPC at the end of GID. Our results are similar to those reported by Bermúdez-Soto et al. ${ }^{11}$ for commercial blackberries. This may be due to the similar digestive conditions used in these studies (control of external oxidizing agents, e.g. light and atmospheric oxygen). As demonstrated by the aforementioned research and the results of the present study, phenolic compounds are highly sensitive to GID conditions. Additionally, the gut microbiota has a key role in phenolic metabolism, breaking down high molecular weight polyphenols to low molecular weight phenolics, which sometimes results in the release of the most bioaccessible and bioactive phenolic compounds with the ability to enter into blood circulation and reach the organs. ${ }^{7-9,18,19,21,27,45,47}$

The total anthocyanin content (TAC, Fig. 1B) of undigested WB was $0.33 \mathrm{mg}$ EC3G per mL compared with $0.22 \mathrm{mg}$ EC3G per $\mathrm{mL}$ for $\mathrm{CB}$; the later value was significantly $(p<0.05)$ lower. Following the OP, TAC values of 0.27 and $0.10 \mathrm{mg}$ EC3G per $\mathrm{mL}$ were observed for $\mathrm{WB}$ and $\mathrm{CB}$, respectively; these values were significantly different $(p<0.05)$. This represents a decrease of $19 \%$ for $\mathrm{WB}$ and $54 \%$ for $\mathrm{CB}$ compared with the undigested samples. During the GP, the TAC of WB varied between 0.16 and $0.18 \mathrm{mg}$ EC3G per $\mathrm{mL}$, and there were no significant differences $(p<0.05)$ between the digestates. The corresponding TAC values varied between 0.18 and $0.19 \mathrm{mg}$ EC3G per $\mathrm{mL}$ for $\mathrm{CB}$, with the $\mathrm{GP}_{90}$ min values being statistically higher $(p<0.05)$ than those of $\mathrm{GP}_{30}$ min and $\mathrm{GP}_{60}$ min. For the IP, the TAC of WB varied between 0.08 and $0.09 \mathrm{mg}$ EC3G per $\mathrm{mL}$. In contrast, the TAC of $\mathrm{CB}$ decreased sequentially during IP and it was significant $(p<0.05)$ after $\mathrm{IP}_{90} \mathrm{~min}$, with values varying between 0.07 and $0.05 \mathrm{mg}$ EC3G per mL. All TAC values of CB during IP were significantly lower $(p<0.05)$ than the corresponding values for WB. At the end of GID, the TAC of the WB digestates decreased by $74 \%$ and the TAC of the CB digestates by $75 \%$, when compared with the undigested samples.

Anthocyanins are flavonoid compounds that are found in Rubus berries and are mainly responsible for their organoleptic properties. These compounds are highly sensitive to changes in $\mathrm{pH}$ and to the presence of enzymes in the matrices. ${ }^{9}$ This 


\section{A. Total Phenolic Content (TPC)}

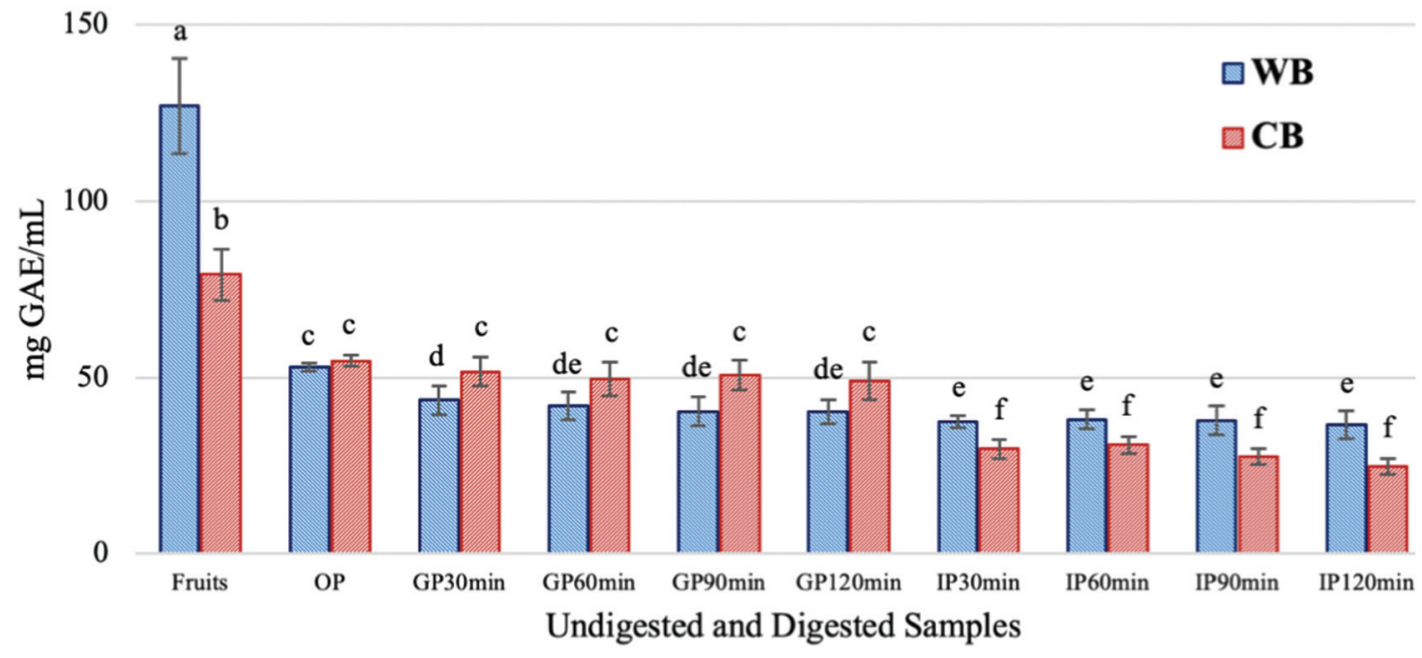

B. Total Anthocyanin Content (TAC)

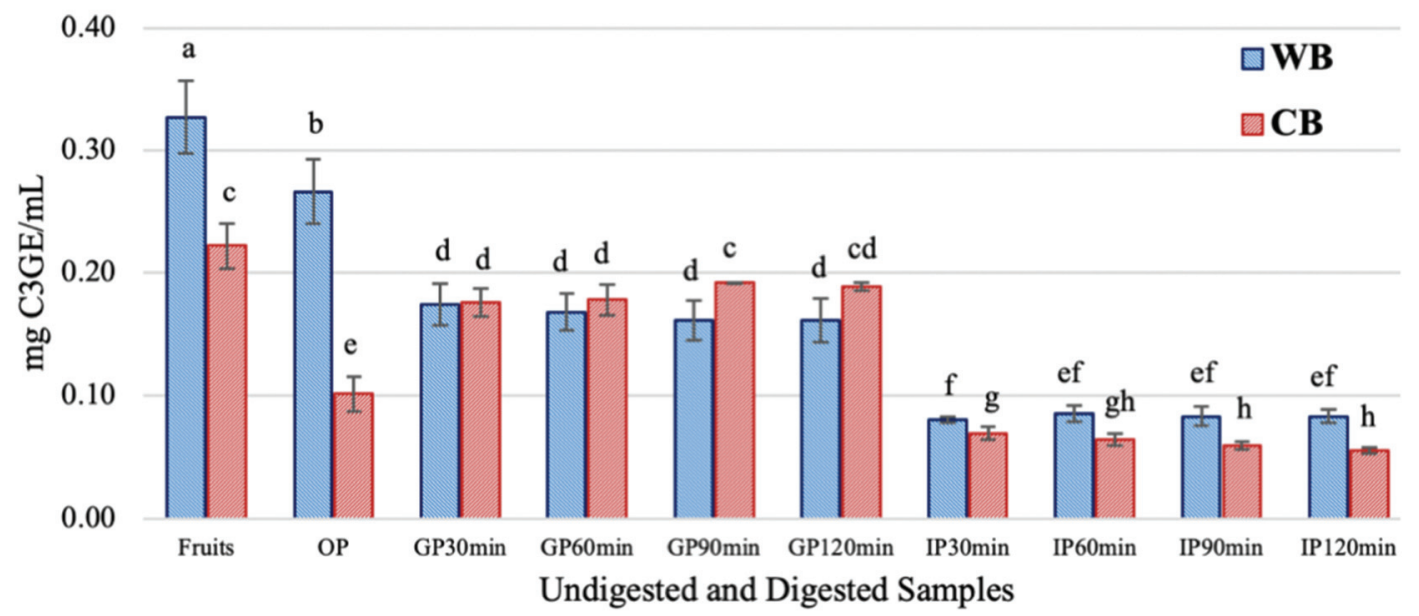

Fig. 1 Total phenolic (A) and anthocyanin (B) contents in undigested and digested WB and CB fruits. WB, wild blackberry; CB, commercial blackberry. $\mathrm{mg}$ GAE per $\mathrm{mL}$, $\mathrm{mg}$ of gallic acid equivalents per $\mathrm{mL}$; $\mathrm{mg}$ C3GE per $\mathrm{mL}$, $\mathrm{mg}$ of cyanidin-3-glucoside per $\mathrm{mL}$. Non-equal letters above bars indicate statistical differences $(p<0.05)$.

sensitivity explains the decrease of up to $97 \%$ in the TAC observed by Ryu and $\mathrm{Koh}^{13}$ for anthocyanin-enriched extracts from $R$. occidentalis after the IP. Similar observations were made by Azofeifa et al. ${ }^{48}$ for $R$. adenotrichos juice, with a decrease in TAC estimated at $88 \%$. Correa-Betanzo et al. ${ }^{49}$ reported a $90 \%$ recovery of polyphenols and/or anthocyanins after gastric digestion of different berries. The release of anthocyanins into the matrix (bolus, chyme or chyle) from the fruit is a gradual process, framed by the different digestive stages, during which the cellular structures of the fruits are exposed to changes in redox potentials, light exposure, transition to an anaerobic atmosphere, and the action of specific enzymes. $^{21,50}$ Considering that, in the current study, the berries were not subjected to an anthocyanin extraction or a semi-purification step, a larger amount of these compounds could be quantified at the end of GID. Another significant factor in the GID simulation was the use of amber flasks as a digestion container, which reduced exposure of the digestates to light, in addition to maintaining a constant flow of nitrogen gas to maintain anaerobic conditions. This helped reduce interference from external factors during GID with the aim of obtaining TAC and TPC values after GID that were more representative of in vivo systems.

\subsection{Changes in anthocyanin and non-anthocyanin profile during GID}

Anthocyanins are a large subclass of phenolic compounds that are found in many edible fruits and vegetables and that exhibit potential health benefits. ${ }^{42,51}$ The basic chemical structure of anthocyanins has the flavylium ion (2-phenyl-benzopyril) as its core and consists of two aromatic groups (a benzopyryl and a phenolic ring). Anthocyanins are found in the vacu- 
oles of plant cells and provide a wide diversity of colors, such as red, purple or blue, to many types of leaves, flowers and fruits. Acylated and glycosylated aglycones of cyanidin (Cy), delphinidin (Dp), malvidin, pelargonidin (Pg), peonidin (Pn) and petunidin (Pt) are often reported in Rubus fruits. ${ }^{42,52}$ Glycosylation (sugar attachment through O-linkages) improves the stability of the anthocyanins and increases their watersolubility. ${ }^{53}$ Several sugar moieties, from monosaccharides to trisaccharides (e.g. galactose, glucose, rutinose, sambubiose, sophorose, or xylose), have been reported to have the ability to attach to the aglycones. Additionally, anthocyanins can undergo greater molecular substitution in Rubus fruits with the addition of acyl or methyl residues to glycosyl moieties. ${ }^{54}$

About 21 acylated and/or glycosylated forms of five aglycones were found in blackberry samples (Table 1). Cy-3-rutinoside (Cy-3-rut) was quantified at $3693 \mu \mathrm{g} \mathrm{mL}^{-1}$ in $\mathrm{WB}$ fruits and $1226 \mu \mathrm{g} \mathrm{mL} \mathrm{m}^{-1}$ in CB fruits, but decreased to $4 \mu \mathrm{g} \mathrm{mL}^{-1}$ in both types of blackberries (BI $-99 \%$ in both cases). It is important to mention that the Cy-3-rut content increased by about $460 \%$ in WB and $314 \%$ in CB during the GP. This anthocyanin was the main one found in $\mathrm{WB}$ and the second most important one found in CB. In WB samples, cyanidin-3-glucoside (Cy-3-glu) was quantified at $2854 \mu \mathrm{g} \mathrm{mL} L^{-1}$ in fruits, but only $8 \mu \mathrm{g} \mathrm{mL} L^{-1}$ in digestate $\mathrm{IP}_{120 \text { min }}$, a decrease of $-99 \%$ in $\mathrm{BI}$, while in CB fruits the corresponding value was $4994 \mu \mathrm{g} \mathrm{mL} \mathrm{m}^{-1}$ and $16 \mu \mathrm{g} \mathrm{mL} \mathrm{m}^{-1}$ at the end of GID (BI of -99\%). This anthocyanin was the most abundant in CB and the second most abundant in WB.

Cy-3-xylosyl-rutinoside (Cy-3-xyl-rut) was quantified at $2215 \mu \mathrm{g} \mathrm{mL} \mathrm{m}^{-1}$ in WB fruits and at $80 \mu \mathrm{g} \mathrm{mL}^{-1}$ in $\mathrm{IP}_{120} \min$ (BI $-98 \%)$; it was not found in CB samples either before or after

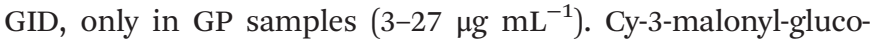
side (Cy-3-mal-glu) was found at a concentration of $466 \mu \mathrm{g} \mathrm{mL}$ in WB fruits; it decreased to $3 \mu \mathrm{g} \mathrm{mL}^{-1}$ in $\mathrm{IP}_{120 \text { min }}$ aliquot $(\mathrm{BI}<$ $1 \%)$, while in $\mathrm{CB}$ fruits it was $160 \mu \mathrm{g} \mathrm{mL} \mathrm{m}^{-1}$ and $2 \mu \mathrm{g} \mathrm{mL} \mathrm{m}^{-1}$ (BI < 2\%). Cy-3-dioxalyl-glucoside (Cy-3-dioxal-glu) was found at a concentration of $21 \mu \mathrm{g} \mathrm{mL} \mathrm{m}^{-1}$ in WB fruits and $19 \mu \mathrm{g} \mathrm{mL} L^{-1}$ after GID (BI of 90\%); in CB samples its content was $613 \mu \mathrm{g} \mathrm{mL} \mathrm{m}^{-1}$ in fruits and 124 at IP 120 min (BI of 20\%). Dp-3-(6-p-coumaroyl)-glucoside (Dp-3-(6-p-cou)-glu) was estimated at $50 \mu \mathrm{g} \mathrm{mL} \mathrm{mL}^{-1}$ in $\mathrm{WB}$ fruits and $17 \mu \mathrm{g} \mathrm{mL}^{-1}$ in digested sample (BI of 66\%), compared with $83 \mu \mathrm{g} \mathrm{mL} \mathrm{m}^{-1}$ in $\mathrm{CB}$ fruits and $21 \mu \mathrm{g} \mathrm{mL^{-1 }}$ in digested $\mathrm{CB}$, which corresponds to a BI of $75 \%$. Pg-3-rutinoside (Pg-3-rut) was found at a concentration of $101 \mu \mathrm{g} \mathrm{mL^{-1 }}$ in WB fruits and only $2 \mu \mathrm{g} \mathrm{mL} \mathrm{m}^{-1}$ after GID, with a BI $<1 \%$; however, it was not detected in CB fruits or digestates. Pt-3-glucoside (Pt-3-glu) was detected at a concentration of $42 \mu \mathrm{g} \mathrm{mL} L^{-1}$ in WB fruits; its concentration increased to $264 \mu \mathrm{g} \mathrm{mL} \mathrm{L}^{-1}$ after GID, for a BI of $629 \%$. In $\mathrm{CB}$ fruits, its concentration decreased from $607 \mu \mathrm{g} \mathrm{mL} \mathrm{m}^{-1}$ to $312 \mu \mathrm{g} \mathrm{mL} \mathrm{m}^{-1}$ after GID, for a BI of $49 \%$.

Two isoforms of Cy-3-glucosylrutinoside (Cy-3-glu-rut-iso 1 and 2) were found in WB fruits: Cy-3-glu-rut-iso 1 was found at a concentration of $30 \mu \mathrm{g} \mathrm{mL} \mathrm{m}^{-1}$ and Cy-3-glu-rut-iso 2 at a concentration of $54 \mu \mathrm{g} \mathrm{mL} \mathrm{m}^{-1}$, respectively. Cy-3-glu-rut isomers were undetected after GID. In CB these anthocyanins were detected only during GP at low concentrations $\left(<12 \mu \mathrm{g} \mathrm{mL}{ }^{-1}\right)$. A similar pattern was observed for other anthocyanins in both fruits: Cy-3-5-diglucoside isomer 1 (Cy-3-5-diglu-iso 1) was found at a concentration of $6 \mu \mathrm{g} \mathrm{mL} L^{-1}$ in $\mathrm{WB}$ and $30 \mu \mathrm{g} \mathrm{mL}^{-1}$ in CB; Cy-3-5-diglucoside isomer 2 (Cy-3-5-diglu-iso 2) at a concentration of 3 and $8 \mu \mathrm{g} \mathrm{mL} \mathrm{m}^{-1}$, respectively, in WB and CB; Cy3-sophoroside (Cy-3-sop) at a concentration of $16 \mu \mathrm{g} \mathrm{mL} \mathrm{L}^{-1}$ and $25 \mu \mathrm{g} \mathrm{mL} \mathrm{m}^{-1}$ in WB and CB fruits, respectively; Cy-3-xylosyl-(feruloyl-glucosyl)-galactoside (Cy-3-xyl-(fer-glu)-gal) at a concentration of $2 \mu \mathrm{g} \mathrm{mL} \mathrm{m}^{-1}$ in WB and not detected in CB; Cy-3-sambubioside (Cy-3-sam) at a concentration of $103 \mu \mathrm{g} \mathrm{mL} \mathrm{m}^{-1}$ in $\mathrm{WB}$ and $14 \mu \mathrm{g} \mathrm{mL} \mathrm{m}^{-1}$ in $\mathrm{CB}$, before digestion; Cy-3-xylosyl-galactoside (Cy-3-xyl-gal) at a level of 103 and $14 \mu \mathrm{g} \mathrm{mL} \mathrm{m}^{-1}$ in WB and $\mathrm{CB}$, respectively; Cy-3-xyloside (Cy-3-xyl) at a level of $14 \mu \mathrm{g}$ $\mathrm{mL}^{-1}$ in $\mathrm{WB}$ and $8 \mu \mathrm{g} \mathrm{mL} \mathrm{m}^{-1}$ in $\mathrm{CB}$; Cy-3-acetyl-glucoside (Cy-3act-glu) was found at a concentration of $35 \mu \mathrm{g} \mathrm{mL} \mathrm{m}^{-1}$ in $\mathrm{CB}$, but it was not detected in WB fruits; Dp-3-glucoside (Dp-3-glu) was estimated at $1 \mu \mathrm{g} \mathrm{mL} L^{-1}$ in $\mathrm{WB}$ and $16 \mu \mathrm{g} \mathrm{mL}^{-1}$ in CB; Dp-3acetyl-glucoside (Dp-3-act-glu) was quantified at $13 \mu \mathrm{g} \mathrm{mL} L^{-1}$ in $\mathrm{CB}$, but it was not detected in WB samples; Pg-3-glucoside (Pg3-glu) was found at a concentration of $67 \mu \mathrm{g} \mathrm{mL} \mathrm{m}^{-1}$ in $\mathrm{WB}$ and $15 \mu \mathrm{g} \mathrm{mL} \mathrm{m}^{-1}$ in $\mathrm{CB}$; Pg-3-malonyl-glucoside (Pg-3-mal-glu) was found at a level of $10 \mu \mathrm{g} \mathrm{mL} \mathrm{m}^{-1}$ in $\mathrm{WB}$, but it was not detected in CB; Pn-3-glucoside (Pn-3-glu) was quantified at $7 \mu \mathrm{g} \mathrm{mL} \mathrm{L}^{-1}$ in both $\mathrm{WB}$ and $\mathrm{CB}$. In all these cases, the BI was $0 \%$.

All concentrations of anthocyanins in WB fruits decreased during the OP; they increased in $\mathrm{CB}$ fruits following this digestive step. It is important to consider the role of $\alpha$-amylase in the cleavage of non-reducing terminal 1-4 linked $\alpha$-glucose residues; a higher content of carbohydrate concentration in $\mathrm{CB}$ could lead to substrate inhibition and interrupt anthocyanin cleavage during OP. ${ }^{55}$ Considering that WB fruits had a higher TAC than $\mathrm{CB}$, anthocyanins may have saturated the salivary amylase, retained them in their carbinol pseudobase/chalcone form, and thus, prevented subsequent enzymatic activity. ${ }^{9,56}$

Frequently, anthocyanins are the first compounds that come into contact with the hostile environment of the mouth during mastication, which is when the metabolism of plant pigments begins. ${ }^{9,57,58}$ The physicochemical conditions in the oral cavity $(\mathrm{pH}$, electrolytes, temperature, darkness, decreasing $\mathrm{O}_{2}$ content, enzymes, etc.) have a negative influence on anthocyanin stability, usually resulting in anthocyanin degradation. ${ }^{6,59}$ First, mastication breaks down the macro- and microstructures of fruit cells during bolus formation, which helps to release anthocyanin. Then atmospheric $\mathrm{O}_{2}$ starts to oxidize the free anthocyanins. The $\mathrm{pH}$ level $(>7.0)$ triggers rapid (30-103 s) hydration of the flavylium cation at C2 (ring C), generating a carbinol pseudobase (it can also further equilibrate to the colorless open-ring chalcone form) and a loss of color. ${ }^{6,9,59}$ Deprotonation continues at a $\mathrm{pH}$ level of >6.0, forming violet-blue quinoidal and anionic bases, which are fully-conjugated cyclic diones. With the addition of water, two electrons are added to the resonant molecules (chalcone or carbinol pseudobase), increasing their electronegativity at C6 and $\mathrm{C} 8$ of ring A. ${ }^{9}$ After chalcone is formed, it undergoes deglycosylation and further chemical degradation.

In addition, enzymatic deglycosylation of the flavylium form generates unstable aglycones, which are then spon- 


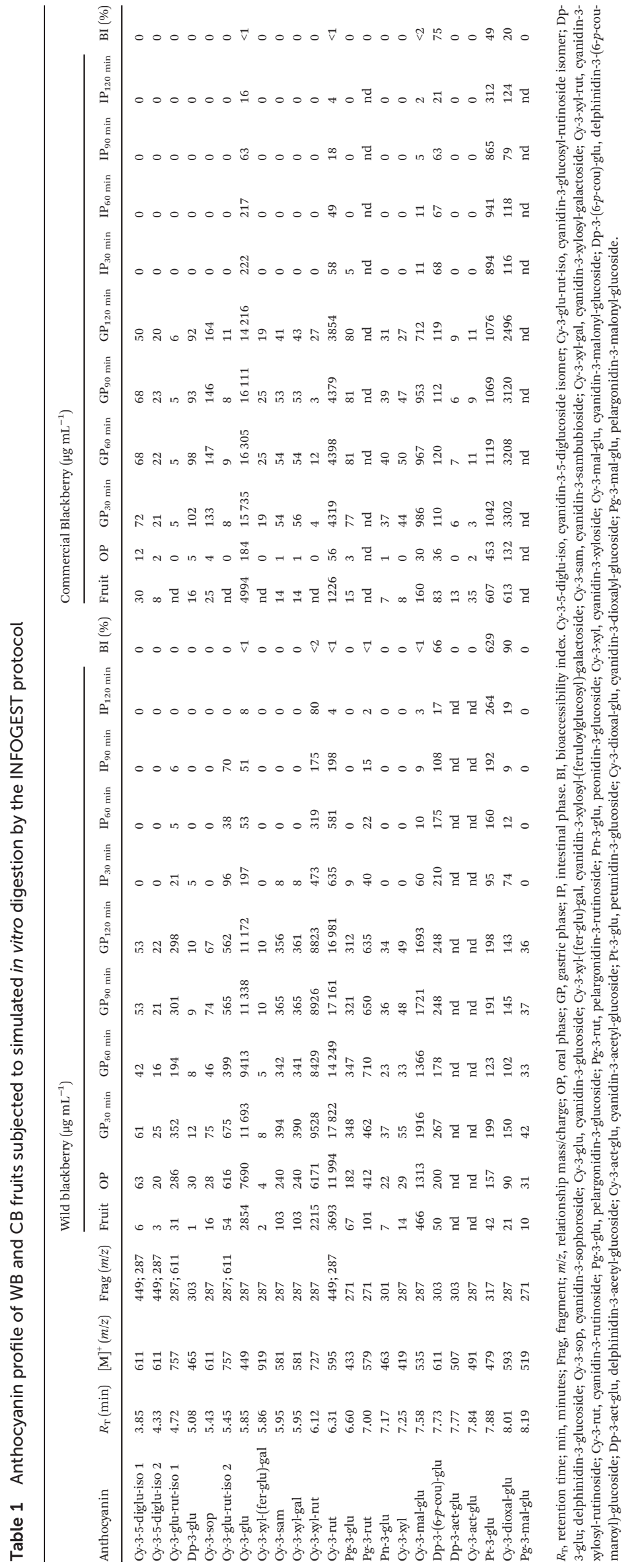




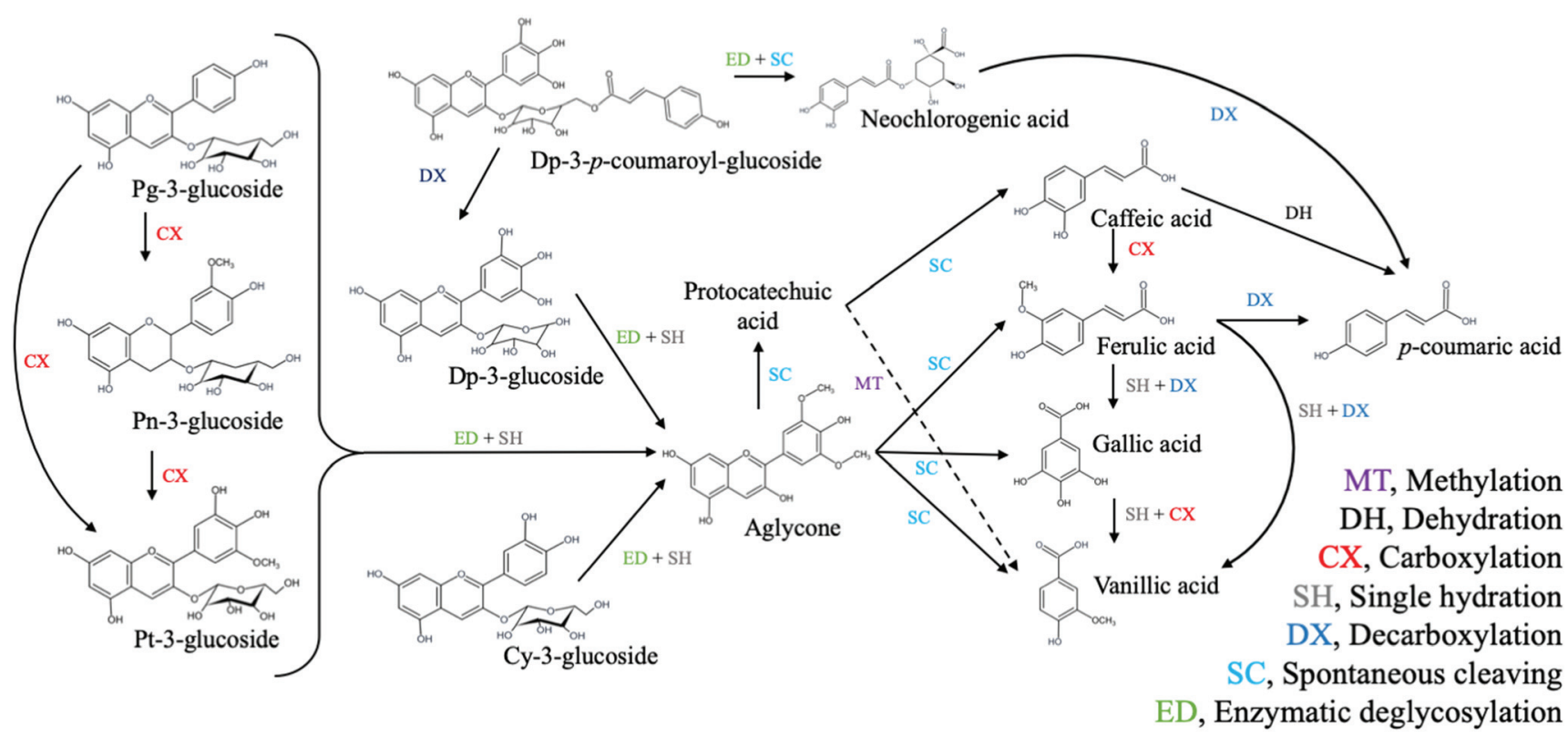

Fig. 2 Polyphenol metabolites implicated in anthocyanin metabolism during GID. Adapted from McGhie et al., ${ }^{60}$ Nurmi et al., ${ }^{61}$ de Ferrars et al. ${ }^{62}$ and Olivas-Aguirre et al. ${ }^{58} \mathrm{Cy}$, cyanidin; Dp, delphinidin; Pg, pelargonidin; Pn, peonidin; Pt, petunidin.

taneously cleaved into phenolic derivatives (Fig. 2). Amylase is the main enzyme synthesized in the oral cavity that contributes to anthocyanin degradation. ${ }^{55}$ The sugar moiety is particularly important to the structural stability of the anthocyanins, and oral glycosidases cleave the glycosydic bond between the aglycone and glycosyl group. Recently, it has been suggested that it is responsible for the glycosylation of anthocyanidins, giving rise to anthocyanins and consecutive derivatives in the mouth. ${ }^{9,55}$ At the same time, amylases release anthocyanins from cell structures as well as large carbohydrates. The most common sub-products of anthocyanin deglycosylation, through spontaneous cleavage of aglycone, are protocatechuic, caffeic, gallic and vanillic acids. The last three phenolics could be produced by other spontaneous cleavage, decarboxylation, carboxylation, single hydration or dehydration processes. ${ }^{6,9,57,58,60-62}$ Since anthocyanins have low bioavailability after GID, the above-mentioned phenolic acids plus $p$-coumaric acid (one of the simplest metabolites of anthocyanins and other phenolic compounds produced during GID) are considered to be bioavailable and bioactive remnants of anthocyanins in the human body. ${ }^{58,63}$

About 12 flavanols and proanthocyanidins found in the WB and $\mathrm{CB}$ samples are listed in Table 2. While the catechin content of WB fruits, initially $48.52 \mu \mathrm{g} \mathrm{mL} \mathrm{m}^{-1}$ and completely degraded after GID, while it remained at $5.32 \mu \mathrm{g} \mathrm{mL} \mathrm{m}^{-1}$ in $\mathrm{CB}$ after GID (BI of 14\%). The isoform of this flavanol, epicatechin, was quantified at $34.51 \mu \mathrm{g} \mathrm{mL} \mathrm{m}^{-1}$ in $\mathrm{CB}$ fruits and $5.35 \mu \mathrm{g}$ $\mathrm{mL}^{-1}$ in the aliquot of $\mathrm{IP}_{120}$ min (BI of $16 \%$ ), while in WB samples its content was $412.19 \mu \mathrm{g} \mathrm{mL}^{-1}$ before GID and $3.91 \mu \mathrm{g} \mathrm{mL} \mathrm{mL}^{-1}$ after GID (BI < 1\%). Quercetin (Qc) and kaempferol (Kf) aglycones were detected at levels of 158.54 and $16.87 \mu \mathrm{g} \mathrm{mL} \mathrm{m}^{-1}$ in $\mathrm{CB}$, respectively, and 385.35 and $47.97 \mu \mathrm{g}$
$\mathrm{mL}^{-1}$ in $\mathrm{WB}$, respectively. These two aglycones were degraded after GID in both types of blackberries. In comparison with these compounds, their glycosylated forms seem to be more resistant to GID: Qc-3-glucoside (Qc-3-glu) was found at a concentration of $21159.74 \mu \mathrm{g} \mathrm{mL} \mathrm{m}^{-1}$ in $\mathrm{CB}$ fruits and then decreased to $8207.35 \mu \mathrm{g} \mathrm{mL} \mathrm{m}^{-1}$ after GID (BI of $39 \%$ ). In WB, its content was $1360.17 \mu \mathrm{g} \mathrm{mL} \mathrm{m}^{-1}$ and then $6163.50 \mu \mathrm{g} \mathrm{mL} \mathrm{m}^{-1}$ after $\mathrm{IP}_{120}$ min (an increase in BI of $453 \%$ ). This flavanol was the major non-anthocyanin phenolic in both types of blackberries. Qc-3-glucoronide (Qc-3-glur) was detected at a level of 4123.47 $\mu \mathrm{g} \mathrm{mL} \mathrm{m}^{-1}$ in CB fruits, dropping to $2240.40 \mu \mathrm{g} \mathrm{mL} \mathrm{m}^{-1}$ after GID (BI of 54\%); it was quantified at 253.04 and $1522.41 \mu \mathrm{g} \mathrm{mL}$ in fruits and digested WB (BI of 602\%). Qc-3-galactoside (Qc-3gal) or hyperoside was found at a level of 4847.24 and $1794.07 \mu \mathrm{g} \mathrm{mL} \mathrm{m}^{-1}$ in fruits and digested CB, respectively (BI of 39\%). Corresponding concentrations of 198.87 and $1415.59 \mu \mathrm{g}$ $\mathrm{mL}^{-1}$ were found in undigested and digested WB (BI of 712\%). Kf-3-glucorinide (Kf-3-glur) was quantified at $1675.19 \mu \mathrm{g} \mathrm{mL}$ in $\mathrm{CB}$ fruits and $1570.54 \mu \mathrm{g} \mathrm{mL} \mathrm{m}^{-1}$ after digestion (BI of 94\%); its concentration was $63.35 \mu \mathrm{g} \mathrm{mL^{-1 }}$ in $\mathrm{WB}$ fruits and $1195.54 \mu \mathrm{g} \mathrm{mL} \mathrm{m}^{-1}$ after GID (BI of 1887\%).

Three isoforms of procyanidin dimers were found in $\mathrm{CB}$ fruits: procyanidin dimer iso-2, iso-3 and $\mathrm{B} 2$ in concentrations of $54.10,41.41$ and $6.33 \mu \mathrm{g} \mathrm{mL}{ }^{-1}$, respectively. In WB fruits, procyanidin dimer iso-1, iso-2, iso-3 and B2 were quantified respectively at $55.24,236.85,7.71$ and $28.96 \mu \mathrm{g} \mathrm{mL} \mathrm{m}^{-1}$. These procyanidins were totally degraded at the end of GID.

Flavanols and proanthocyanidins have low bioavailability in the human body. Salivary exposure has been found to produce no large changes in these phenolics, which is inconsistent with our findings. ${ }^{64} \mathrm{~A}$ mild acidic environment is the main factor responsible for oligomeric proanthocyanidin or flavanol 


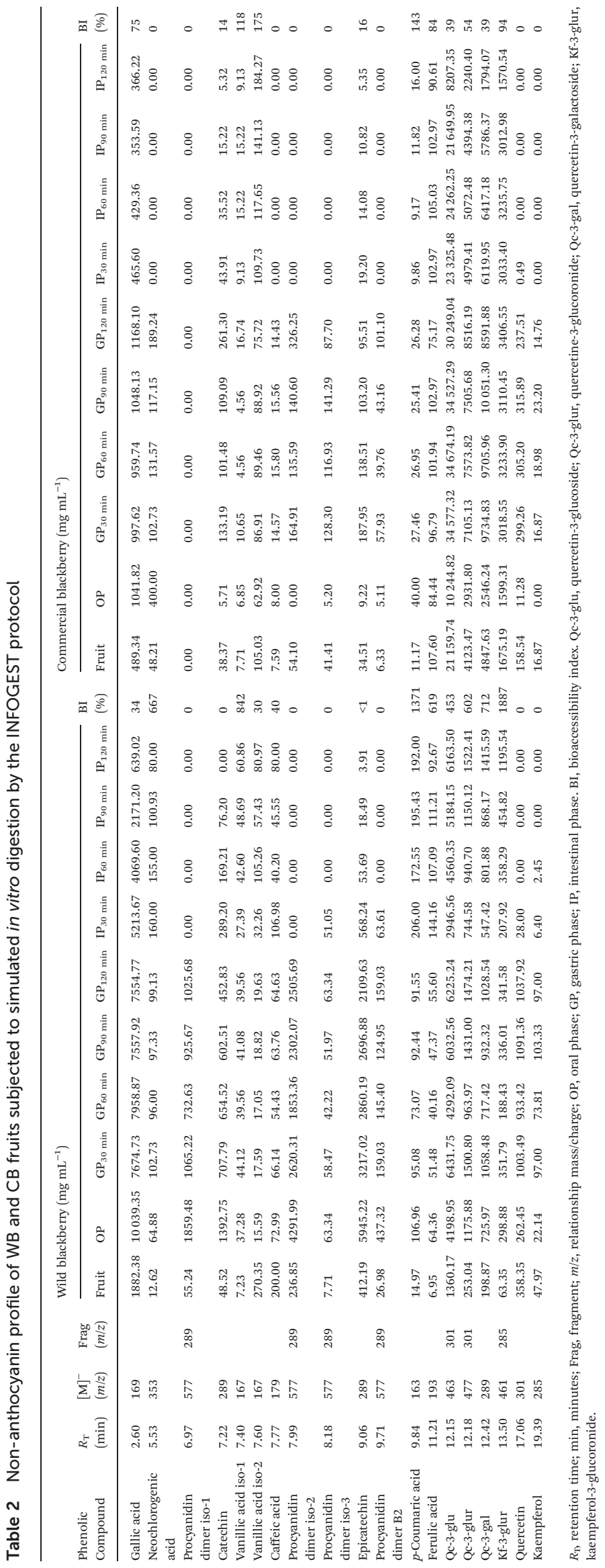


(>2000 Da) depolymerization. This breakdown may be good for the stability of dimeric procyanidins and acylated and aglycones of flavanols, ${ }^{64}$ which could explain the increase in the concentration of these proanthocyanidins and flavanols during the GP. However, following the addition of pancreatic enzymes during the IP, their degradation is promoted, and glycosylated flavanols are progressively degraded, resulting in stable final products like phenolic acids, including gallic, ferulic, vanillic and hydroxybenzoic acids. ${ }^{65}$

The six phenolic acids profiled in both types of blackberries are displayed in Table 2. Phenolic acids are the major metabolites of tannins, anthocyanins, flavanols and other polyphenol metabolism before absorption by the gut epithelium or their total degradation. ${ }^{63}$

The gallic acid content was quantified at $489.34 \mu \mathrm{g} \mathrm{mL} \mathrm{L}^{-1}$ and $366.22 \mu \mathrm{g} \mathrm{mL} L^{-1}$ in $\mathrm{CB}$ fruits and the digestate $\mathrm{IP}_{120 \mathrm{~min}}$, respectively (BI of $75 \%$ ). In $\mathrm{WB}$, this phenolic acid was found at levels of 1882.38 and $639.02 \mu \mathrm{g} \mathrm{mL} \mathrm{m}^{-1}$ in undigested and digested fruits, respectively (BI of $34 \%$ ). Gallic acid is a hydroxybenzoic acid present in $R$. liebmannii in the form of hydrolysable (gallotannins and ellagitannins) and condensed (proanthocyanidins) tannins. ${ }^{66}$ Despite the fact that gallic acid is unstable under alkaline conditions, its content increased in both types of fruit following the OP, possibly due to its liberation from the matrix by $\alpha$-amylase. Gallic acid is released into the digestive matrix from metabolized proanthocyanidins, gallotannins and ellagitannins during degeneration of the cell structures of fruits, such as vacuoles and cell walls, by mechanical action, but particularly by enzymatic activity via non-covalent interactions between gallic acid- $\alpha$-amylase. ${ }^{66}$ Gallic acid could be a product of tannin hydrolysis, spontaneous cleavage of the cyanidin aglycone, or a single hydration + carboxylation of ferulic acid. ${ }^{6,62,67}$ The short time of exposure to mouth conditions could result in irreversible changes to gallic acid molecules, including enzymatic hydrolysis, depolymerization and deglycosylation, ${ }^{9,68}$ which are more evident than in the GP, since proteases (pepsin) and low $\mathrm{pH}(\leq 3)$ may favor the release of this phenolic acid and maintain its chemical stability in the food matrix. ${ }^{69}$ Agudelo et al. ${ }^{70}$ also reported an increase in gallic acid content during mouth and stomach simulation of the digestion of the Andean berry (Vaccinium meridionale). This is one of the most bioaccessible, bioactive and bioavailable phenolics in this fruit.

Neochlorogenic acid was not detected in CB samples after GID but it was found at a level of $48.21 \mu \mathrm{g} \mathrm{mL}^{-1}$ in fruits. In $\mathrm{WB}$, it was quantified at $12.62 \mu \mathrm{g} \mathrm{mL}^{-1}$ and $80.00 \mu \mathrm{g} \mathrm{mL} L^{-1}$ in fruits and digestate, respectively (BI of 667\%). Neochlorogenic acid is an isomer of chlorogenic acid, a hydroxycinnamic acid derived from caffeic acid; it is commonly found in many berry fruits. ${ }^{27,47,71}$ It is also a metabolite of acylated anthocyanins, specifically Dp-3-p-cou-glu, resulting from enzymatic deglycosylation + spontaneous cleavage. ${ }^{9,68}$ In contrast to the results found in the present study for CB digestates, the neochlorogenic acid content was found to decrease by $28 \%$ in chokeberries (Aronia melanocarpa) ${ }^{11}$ and by $55 \%$ in blueberries (Vaccinium sp. $)^{12}$ after GID digestion; however, it was not totally degraded, as was the case in digested WB fruits. In black mulberry (Morus sp.) wine, the chlorogenic acid content decreased by $43 \%$ during GID digestion. ${ }^{72}$ The non-detection of neochlorogenic acid in commercial blackberry IP digestates could be due to its isomerization under pancreatic incubation conditions, not just its degradation. ${ }^{11}$

Two isomers of vanillic acid (iso-1 and iso-2) were found in both types of blackberries: vanillic acid iso-1 was quantified at $7.71 \mu \mathrm{g} \mathrm{mL} L^{-1}$ and $9.13 \mu \mathrm{g} \mathrm{mL} L^{-1}$ in undigested and digested $\mathrm{CB}$ fruits, respectively (BI of 118\%). Its content was $7.23 \mu \mathrm{g} \mathrm{mL}$ in WB fruits and $60.86 \mu \mathrm{g} \mathrm{mL} \mathrm{m}^{-1}$ after GID (BI of $842 \%$ ). The concentration of vanillic acid iso-2 was $105.03 \mu \mathrm{g} \mathrm{mL} \mathrm{m}^{-1}$ and $184.27 \mu \mathrm{g} \mathrm{mL}^{-1}$ in CB before and after GID, respectively (BI of $175 \%)$. In WB samples, it was found at a level of $270.35 \mu \mathrm{g}$ $\mathrm{mL}^{-1}$ in fruits and $80.97 \mu \mathrm{g} \mathrm{mL} \mathrm{m}^{-1}$ in the digestate $\mathrm{IP}_{120 \text { min }}(\mathrm{BI}$ of $30 \%)$. Vanillic acid isoforms are derivatives of the hydroxybenzoic acid structure that is present in berry fruits or digested products in its native form, or as a metabolite from anthocyanins, flavanols or hydroxycinnamic acids. ${ }^{47,61}$ Vanillic acid isomers may be produced by spontaneous cleavage of anthocyanidins (like cyanidin), methylation of protocatechuic acid and/or single hydration + carboxylation of gallic acid. ${ }^{60,61}$ During in vitro GID of blueberries (Vaccinium myrtillus), the content of vanillic acid decreased from the $0.08 \mathrm{mg} \mathrm{g}^{-1}$ fresh weight level until it was undetectable. ${ }^{68}$ Nurmi et al. ${ }^{61}$ found an increase in homovanillic ( $+23 \%)$ and vanillic acids $(+57 \%)$ in a mixed extract of blueberries (Vaccinium myrtillus) and lingonberries (Vaccinium vitis-idaea) after in vivo metabolism. Vanillic acid isoforms are recognized as products of protocatechuic acid metabolism, which in turn is produced by the hydrolysis of anthocyanins; this may explain the increase in the concentration of this phenolic acid at the end of GID. ${ }^{62}$

Caffeic acid was quantified at $7.59 \mu \mathrm{g} \mathrm{mL}^{-1}$ in $\mathrm{CB}$ fruits, but it was not detected after GID. In contrast, in WB it was found at a concentration of 200.00 and $80.00 \mu \mathrm{g} \mathrm{mL} \mathrm{L}^{-1}$ before and after digestion of the fruits, respectively (BI of $40 \%$ ). Caffeic acid is a hydroxycinnamic acid, the main metabolites of which are vanillic acid isomers, which could be produced by spontaneous cleavage of protocatechuic acid. ${ }^{47,58}$ The metabolism of this phenolic compound could contribute to the increase in vanillic acid isoforms. In the Andean berry, the caffeic acid content decreased by $74 \%$ after the $\mathrm{IP}^{70}$ (a bigger decrease than in CB digestates, but smaller than in WB samples). An experiment with blueberry-lingonberry extract showed that $<10 \%$ of ingested caffeic acid was recovered. Additionally, its intact chemical structure showed low bioavailability and bioaccessibility in comparison with its metabolites: 3-caffeoylquinic, 4-caffeoylquinic, ferulic and/or $p$-coumaric acids. ${ }^{73}$

Ferulic acid was found at a concentration of $107.60 \mu \mathrm{g} \mathrm{mL}^{-1}$ in $\mathrm{CB}$ fruits and at $90.61 \mu \mathrm{g} \mathrm{mL} \mathrm{m}^{-1}$ after digestion (BI of $84 \%$ ), compared with $6.95 \mu \mathrm{g} \mathrm{mL} \mathrm{m}^{-1}$ in WB fruits and 92.67 after GID (BI of 619\%). It is known that ferulic acid moieties can stabilize anthocyanins, which can generate co-pigmentation in the matrix even at $\mathrm{pH}$ 3.0-4.0 (such as in fruits or during the GP) $;^{59,62}$ however, this compound is also an intermediate 
product of the catabolism of these flavonoids, the spontaneous cleavage of the B-ring of cyanidin aglycone and protocatechuic acid, or the spontaneous carboxylation of caffeic acid in the gastrointestinal tract. ${ }^{6,9,57,62}$

In $\mathrm{CB}, p$-coumaric acid was found at levels of 11.17 and $16.00 \mu \mathrm{g} \mathrm{mL}^{-1}$ in fruits and digested samples (BI of $143 \%$ ), whereas in WB its concentration was 14.97 and $192.00 \mu \mathrm{g}$ $\mathrm{mL}^{-1}$ in fruits and digested samples (BI of 1371\%). $p$-Coumaric acid, a hydroxycinnamic acid, is found in blackberry fruits in moderate concentrations, but its content increases with the metabolism of cyanidin anthocyanins during GID, for example, via dehydration of caffeic acid and/or decarboxylation of ferulic and neochlorogenic acids. ${ }^{6,58,60,74}$ In blueberry fruits, Gapski et al. ${ }^{73}$ observed that this phenolic compound was not reported after in vivo GID. It has been found in the bloodstream after berry consumption, which may be due to the metabolism of free phenolic acids, such as caffeic or ferulic acids, or degradation of flavonoids, including cyanidin and quercetin derivatives. ${ }^{75,76}$

Polyphenols from red fruits are released into the digestive matrix and metabolized by the above-mentioned processes; however, it should be noted that other factors, such as oral, stomach and gut microbiota, and absorption during the three GID steps, have a strong influence on polyphenol bioaccessibility and bioavailability. ${ }^{77}$ There is no consensus on the bioavailability of phenolic compounds with high molecular weight $\left(>450 \mathrm{~g} \mathrm{~mol}^{-1}\right.$ ), such as anthocyanins, flavanols and tannins. Native high molecular weight polyphenols are undetected or detected in very low amounts after digestion in plasma, tissues or urine. ${ }^{78}$ This is because these phytochemicals are recognized as compounds with variable bioaccessibility and low bioavailability. ${ }^{77}$ However, their metabolites are frequently found in body fluids in concentrations that do not correspond with their contents in fruits. ${ }^{73}$

The digestion conditions are one of the main factors responsible for the biotransformation of these compounds; however, gut microbiota, interactions with other macro- and micro-compounds in the food matrix, age, health conditions, sex, and other factors are implicated in the profiling of polyphenol intake. ${ }^{78}$ Thus, digestion increases the amount of phenolic metabolites (low molecular weight phenolics), enhancing their bioaccessibility, which could have a direct effect on their bioavailability and bioactivity. ${ }^{79}$ More studies are required to better understand the in vivo effects of digestion and metabolism of phenolics and other phytochemicals.

\subsection{In vitro antioxidant activity}

The antioxidant capacity (AOX) of fruits is directly related to their chemical profile. Phenolics are the most important antioxidant phytocompounds in Rubus fruits. ${ }^{42}$ Phenolic anti radical activity follows the HAT or SET mechanisms, or both, depending on many factors (e.g., pH of the matrix and chemistry of the antioxidant agents). ${ }^{26}$ The results of five in vitro bioactivity assays are summarized in Table 3 .

3.4.1 ORAC. The results obtained with the ORAC assay showed higher AOX in WB fruits compared with $\mathrm{CB}$ fruits

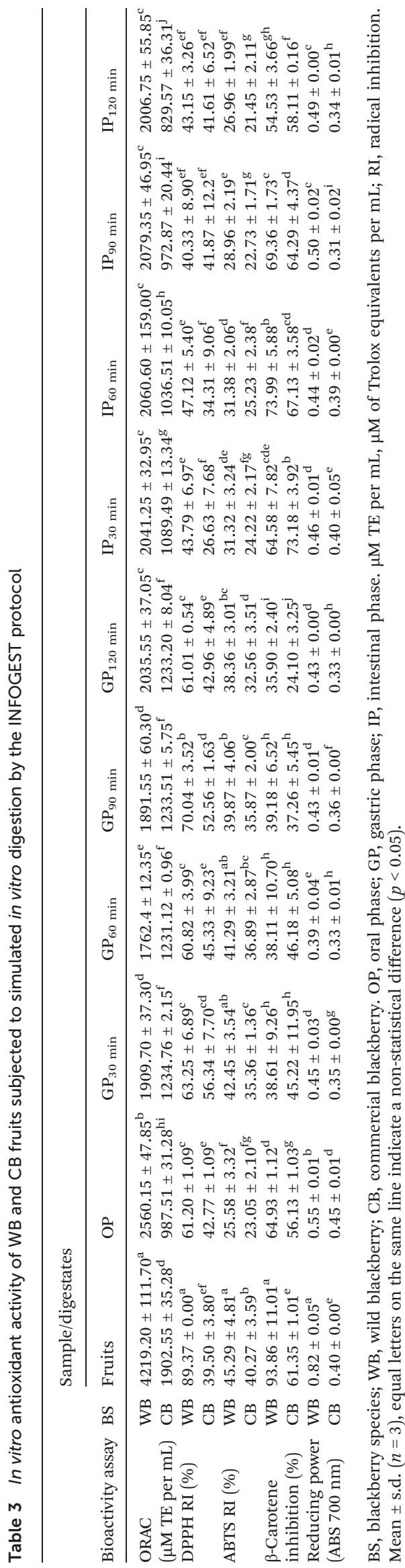

This journal is (c) The Royal Society of Chemistry 2021 
(4219.20 and 1902.55 $\mu \mathrm{M}$ TE per $\mathrm{mL}$, respectively). Following the OP, the AOX of both types of fruit was drastically decreased. Afterward, it increased again in CB, reaching a constant value until $\mathrm{GP}_{120}$ min. The value for $\mathrm{WB}$ at $\mathrm{GP}_{120}$ min was lower $(p<0.05)$ than that for the undigested fruits; it was also lower following the OP, at $2035.55 \mu \mathrm{M}$ TE per mL. After that, the AOX for WB did not change, whereas it declined to 829.57 $\mu \mathrm{M}$ TE per $\mathrm{mL}$ in $\mathrm{CB}$ at the end of GID. The results showed statistically $(p<0.05)$ higher values in WB compared with those in $\mathrm{CB}$ at every single GID stage. The AOX of $\mathrm{IP}_{120}$ min digestates for $\mathrm{WB}$ and $\mathrm{CB}$ decreased by $52 \%$ and $56 \%$, respectively, compared with the values for undigested fruits. The ORAC assay measures the capacity of an antioxidant to scavenge $\mathrm{H}_{2} \mathrm{O}_{2}{ }^{\circ}$ produced by the AAPH radical generator. Free phenolic acids and other metabolites of anthocyanins, flavanols and tannins from berries have a high antioxidant effect on $\mathrm{H}_{2} \mathrm{O}_{2}{ }^{*}$, which is one of the major radicals produced in the human body and may cause cellular damage to membrane lipids, DNA and other valuable macromolecules. ${ }^{42,48}$ Phenolic acids and flavonoids with free $\mathrm{OH}$ groups are free-radical scavengers that are able to interrupt oxidation chains via the HAT mechanism. These phenolics inhibit the degradation of fluorescence after being mixed with an azo-initiator (AAPH·), which generates ROO at body temperature. ${ }^{29}$

Undigested samples of WB had AOX similar (>3800 $\mu \mathrm{M}$ TE per $\mathrm{mL}$ ) to that reported by Sánchez-Velázquez et $a l^{16,66}$ in wild blackberries ( $R$. liebmannii and $R$. palmeri) collected in Sinaloa during the 2014 season, but higher than that of CB. Fresh fruits of wild $R$. croceacanthus and $R$. sieboldii showed ORAC values of $>4000 \mu \mathrm{mol}$ TE per $\mathrm{mL}$, closer to that of $\mathrm{WB}$, but in commercial fruits of $R$. idaeus ORAC showed a value of $\sim 2000 \mu \mathrm{mol}$ TE per $\mathrm{mL},{ }^{80}$ similar to that of CB. Cerezo et al. ${ }^{81}$ observed that the AOX of the Camarosa strawberry (Fragaria $\times$ ananassa) as determined by the ORAC assay decreased by $43 \%$ after GID. Tavares et $a .^{46}$ reported a decrease of $83.1 \%$ in the AOX of cultivated blackberries after GID. However, in R. adenotrichos, no statistical difference was found between undigested and digested juice. ${ }^{48}$ Alternatively, Chiang et $a .^{82}$ found that, during digestion of European currant fruits, antioxidant capacity increased by up to $11 \%$. With respect to GID of black elder (Sambucus nigra), Zhou ${ }^{83}$ observed a 19\% decrease in the antioxidant capacity as evaluated by ORAC; however, the OP was omitted in this model. As for the black elderberry, our results showed a decrease of $52.43 \%$ in the antioxidant capacity of WB and a decrease of $56.39 \%$ in CB as assessed by the ORAC method. Despite the fact that numerous studies, in which commercial and wild fruit matrices were subjected to in vitro digestion, have shown that digestion improves their antioxidant activity, ${ }^{48,82,84,85}$ more research is required to harmonize the digestion methods, to evaluate the impact during different digestive stages, and to determine which compounds are responsible for the AOX activity found.

3.4.2 DPPH scavenging activity. The inhibition rate (IR) of DPPH radicals in WB fruits was $89.37 \%$, compared to $39.50 \%$ for $\mathrm{CB}$ fruits. The inhibition rate in WB decreased to $61.20 \%$ following the OP and it was not statistically different at
$\mathrm{GP}_{120} \mathrm{~min}$. On the other hand, the value for $\mathrm{CB}$ fruits did not change during OP as it did in the undigested fruits; however, it increased to $56.34 \%$ at $\mathrm{GP}_{30}$ min and then decreased to $42.96 \%$ at $\mathrm{GP}_{120}$ min. The $\mathrm{AOX}$ of $\mathrm{WB}$ at $\mathrm{IP}_{30}$ min was $43.79 \%$ and there was no statistically significant change $(p<0.05)$ during the IP. However, the AOX values for $\mathrm{CB}$ increased $(p<0.05)$ from $26.63 \%$ to $41.61 \%$ between $\mathrm{IP}_{30 \text { min }}$ and $\mathrm{IP}_{120 \mathrm{~min}}$.

After GID, the AOX of WB fruits was less than 50\% of the value for undigested fruits. Despite the variations in the IR during GID of $\mathrm{CB}$, no statistical difference $(p<0.05)$ was observed between the undigested fruits and the final GID digestate. The DPPH radical antioxidant method is a popular method for determining antioxidant activity; this involves monitoring the decrease in the initial absorbance of the radical at $517 \mathrm{~nm} .^{28} \mathrm{DPPH}$ - is easily reduced by the action of flavonoids (like quercetin) via HAT or sequential proton loss electron transfer (SPLET) mechanisms, depending on the polarity of the medium. Independently of this, at the end of the reaction, the structure of the flavonoid is stabilized after the loss of one or two $\mathrm{H}^{+}$from the $\mathrm{OH}$ group at positions $\mathrm{A}$ 7, B4' or B5' and subsequent opening of the $\mathrm{C}$ ring. ${ }^{29}$ The A7-OH group has a key role as the main molecular site of ionization and electron $\left(\mathrm{e}^{-}\right)$transfer, following a SPLET mechanism in flavonoids. ${ }^{86-88} \mathrm{DPPH} \cdot$ is quenched after a $\mathrm{H}^{+}$or electron $\left(\mathrm{e}^{-}\right)$ is accepted from hydroxycinnamic acids to become $\mathrm{DPPH}_{2}$. Low molecular weight phenolic acids can easily remove one DPPH radical from the medium, but their polymers or flavonoids may scavenge more than two of these radicals through the strong density of the rings A and B. However, an additional mechanism may be present in the DPPH - quenching chain, specifically single-electron transfer followed by proton transfer (SET-PT) ${ }^{89}$ However, very few data are available on this mechanism for polyphenols in a digestive matrix.

At a concentration of $100 \mu \mathrm{g} \mathrm{mL} \mathrm{m}^{-1}$, ethanolic extracts from wild fruits of $R$. alpestris, $R$. fraxinifolius and $R$. moluccanus showed DPPH. inhibition of $95 \%, 59 \%$ and $86 \%$, respectively, ${ }^{90}$ where $R$. alpestris and $R$. moluccanus had an AOX similar to that of undigested WB, but all of them were considerably higher than that of CB. By digesting an extract rich in polyphenols from the Chilean strawberry, Thomas-Valdés et $a{ }^{85}{ }^{85}$ reported that the antioxidant capacity evaluated by DPPH increased by $27.15 \%$ when subjected to GID, using the INFOGEST protocol. Azofeifa et al. ${ }^{48}$ also reported an increase of $3.77 \%$ in the IR of digestates from $R$. adenotrichos. However, in a study using pulp from Vitis vinifera, Corrêa et al. ${ }^{91}$ found no significant changes between the undigested samples and after GID. Zhou ${ }^{83}$ observed a decrease in phenolics and anthocyanins during GID of black elderberry (Sambucus nigra) and a corresponding decrease of more than $75 \%$ in antioxidant activity as assessed by DPPH.

3.4.3 ABTS scavenging activity. The inhibition rate (IR) of ABTS radicals in $\mathrm{WB}$ and $\mathrm{CB}$ fruits showed statistically different $(p<0.05)$ values of $45.29 \%$ and $40.27 \%$, respectively. During the OP, inhibition was significantly decreased to $25.58 \%$ and $23.05 \%$ for $\mathrm{WB}$ and $\mathrm{CB}$, respectively, but these values were not statistically different $(p<0.05)$. The result rep- 
resents a decrease of $>40 \%$ of inhibition of ABTS. Nevertheless, at $\mathrm{GP}_{30}$ min the IR increased again to a value similar to that obtained for undigested WB and it remained stable until $\mathrm{GP}_{90}$ min, and subsequently decreased to $38.36 \%$ at $\mathrm{GP}_{120}$ min. The IR of CB samples was not statistically affected during the GP. However, during the IP, the AOX for both fruits decreased, reaching $26.96 \%$ and $21.45 \%$ in $\mathrm{WB}$ and $\mathrm{CB}$, respectively, at the end of GID. Both the HAT and SET mechanisms are reported in the ABTS method because ABTS solubility is not influenced by the $\mathrm{pH}$ of the medium. Therefore, the use of this assay alone to determine the possible antioxidant mechanisms of the assayed compounds is not recommended. ${ }^{92}$ ABTS is oxidized by oxidants to its radical cation (ABTS ${ }^{+}$), thus, AOX is measured through the ability of test compounds to decrease the color by reacting directly with the ABTS $\cdot{ }^{29}$

Abu Bakar et al. ${ }^{90}$ evaluated the TEAC in ethanolic extracts of wild fruits of $R$. alpestris, $R$. fraxinifolius and $R$. moluccanus and found an AOX of $0.73,0.75$ and $0.79 \mathrm{mg}$ of ascorbic acid equivalent per $\mathrm{g}$ of dry sample, respectively. The authors attributed this to the high content of phenolic compounds, similar to that found in WB and CB. In their work, Mihailovic et al. ${ }^{93}$ found an antioxidant capacity of $39.5 \mu \mathrm{M}$ TE per $\mathrm{g}$ for a fresh wild raspberry extract rich in polyphenols, flavonoids and anthocyanins that was subsequently subjected to GID. However, the contribution of these phenolics to AOX was not reported. During the GID of commercial raspberry, Gião et $a l .{ }^{38}$ did not find a significant difference in AOX, as evaluated by the ABTS method, between the undigested sample and the value measured after OP. However, a significant decrease of $>70 \%$ was observed for AOX during the GP (relative to the OP). Following the GP stage, the AOX values increased to a value higher than that before GID, possibly because phenolics are more stable and still exhibit their AOX at an acidic $\mathrm{pH}^{26,48}$ Using INFOGEST, a study on a polyphenol-rich extract from the Chilean strawberry (Fragaria chiloensis) found that the antioxidant capacity was reduced by $47.66 \%$ when it was subjected to GID. ${ }^{85}$ In this study, we obtained maximum antioxidant capacity values for undigested samples and during the gastric stage, a finding that is attributable to the stability of anthocyanins and other polyphenols that are stable under the digestive conditions of the stomach, but are easily degraded in the small intestine. This could explain the decrease in antioxidant capacity of up to $40.47 \%$ in WB and $46.73 \%$ in CB, as assessed by ABTS at the end of the IP. The use of both the ABTS and ORAC assays is recommended for measuring the AOX of phenolics in intestinal digestates at a $\mathrm{pH}$ of 7 . However, it is necessary to use other AOX methods as well to confirm the radical scavenging activity. ${ }^{26,29}$

3.4.4 $\beta$-Carotene bleaching activity. The bleaching rate of $\beta$-carotene was $93.86 \%$ and $61.35 \%$ for $\mathrm{WB}$ and $\mathrm{CB}$ fruits, respectively. These values decreased during the OP (to $64.93 \%$ in $\mathrm{WB}$ and $56.13 \% \mathrm{CB}$ ) and during the GP, reaching $35.90 \%$ in $\mathrm{WB}$ and $24.10 \%$ in $\mathrm{CB}$ at $\mathrm{GP}_{120}$ min. Following the GP, a major increase was observed for $\mathrm{CB}$ at $\mathrm{IP}_{30}$ min $(p<0.05)$, and it was slightly higher than the corresponding value for $\mathrm{WB}$ at $\mathrm{IP}_{30} \mathrm{~min}$ and higher than that at $\mathrm{IP}_{120}$ min. When $\beta$-carotene is exposed to $\mathrm{O}_{2}$, it starts a chain of reactions (a series of rotations and vibration interactions with the solvent) that result in a yellowish-orange medium. ${ }^{29}$ Phenolics incorporated into $\beta$-carotene$\mathrm{O}_{2}$ water may prevent the oxidation of $\beta$-carotene, and thus, its AOX may be estimated according to a HAT mechanism. ${ }^{28}$

The $\beta$-carotene bleaching activity found in $10 \mu \mathrm{g}$ TPC per $\mathrm{mL}$ of extracts from nine Brazilian blackberry cultivars ranged from 30 to $70 \% .{ }^{94}$ Undigested WB showed a higher $\beta$-carotene bleaching activity than these nine Rubus varieties, but the results of CB agree with these genotypes. The $\mathrm{O}_{2}{ }^{-}$inhibition of different fruits of domesticated blackberry genotypes was $40-74 \%,{ }^{95}$ which was lower than the value reported for $\mathrm{WB}$, but similar to the value reported for CB. Corrêa et al. ${ }^{91}$ observed a $36 \%$ increase in the ability to inhibit $\mathrm{O}_{2}{ }^{*}$ during the digestion of Vitis vinifera pulp. Our results showed a final decrease of $41.77 \%$ in the ability to inhibit $\mathrm{O}_{2}{ }^{\circ}$ in WB and only $5.28 \%$ in CB. The final AOX value as obtained by using this method for various food materials subjected to GID has been reported and compared against other antioxidant capacity protocols; ${ }^{96}$ however, they were not used to compare the AOX values of the sample before and after GID. Since the $\beta$-carotene bleaching method employs the $\mathrm{O}_{2}{ }^{*}$ radical, it can be considered an antioxidant evaluation protocol similar to that occurring under physiological redox conditions. ${ }^{28}$

3.4.5 Reducing power. The reducing power (RP) of both types of fruit was affected during GID. An Abs of 0.82 was observed in WB fruits, compared with 0.40 in CB. Following the OP, the Abs decreased to 0.55 in $\mathrm{WB}$ and 0.45 in $\mathrm{CB}$. WB showed values of 0.45 between $\mathrm{GP}_{30}$ min and $\mathrm{GP}_{120}$ min, with no significant difference $(p<0.05)$ during this stage. The Abs of CB showed a statistically significant decrease to 0.33. At the end of the IP, the value for WB was 0.49 , which was higher than the values observed during the GP. CB did not show a statistically significant difference $(p<0.05)$ between $\mathrm{GP}_{120}$ min and $\mathrm{IP}_{120} \mathrm{~min}$. The reducing power decreased by $56 \%$ in WB digestates compared with undigested samples; the RP of WB decreased by $40 \%$ during GID. CB showed a decrease of $15 \%$ at the end of GID. The AOX of WB was statistically $(p<0.05)$ higher than that of CB.

The RP method measures the ability of an antioxidant (or any other molecule) to donate an electron to a radical. It is based on the reduction of a ferroin analog, the $\mathrm{Fe}^{3+}$ complex of tripyridyltriazine $\mathrm{Fe}^{3+} \cdot{ }^{28}$ The $\mathrm{Fe}^{3+}$ reducing power is a useful method that may emulate the ability of ingested phenolics to modulate the redox tone in plasma and tissues through the HAT mechanism. ${ }^{29}$ An ethanolic extract from fruits of R. ellipticus (100-200 $\mathrm{mg} \mathrm{L}^{-1}$ ) showed an Abs of $0.43-1.11 .{ }^{97} \mathrm{It}$ is important to mention that WB showed values similar to the highest concentrations of $R$. ellipticus $\left(150-200 \mathrm{mg} \mathrm{L}^{-1}\right.$ ), and CB had barely less RP than the lowest tested amount of $R$. ellipticus fruit extract. In contrast with our findings, a study on a pomace of grapes (Vitis vinifera) showed that the reducing power increased by $36 \%$ after GID. ${ }^{91}$ The difference in results may be attributable to the fact that the digestive conditions differed between the two studies and to the use of an extract from grapes in the other study. 


\subsection{Cellular bioactivity}

Many studies suggest that in vitro assays on food antioxidants need to be supported by cellular assessment to elucidate the physiological anti-radical activity in the human body. ${ }^{35,36}$ Cellular bioactivity results for berry digestates indicate that the phenolics in these fruits contribute to enhanced CAA, inhibition of oxidative stress, apoptosis, aging, or neurological diseases. ${ }^{29,46,57,71,98}$ The cytotoxicity, CAA, inhibition of ROS-synthesis effects on Caco-2 cells of digested and undigested $\mathrm{WB}$ and $\mathrm{CB}$ samples are summarized in Table 4 .

3.5.1 Cytotoxicity in Caco-2 cells. The cytotoxicity of the undigested samples of $\mathrm{WB}$ and $\mathrm{CB}$ showed mean-maximum effective concentration $\left(\mathrm{EC}_{50}\right)$ values of $0.50 \mathrm{mg}$ GAE per $\mathrm{mL}$ and $1.20 \mathrm{mg}$ GEA per $\mathrm{mL}$, respectively, with significant differences $(p<0.05)$ between them (Table 4). However, with GID, the $\mathrm{EC}_{50}$ was $1.14 \mathrm{mg}$ GAE per $\mathrm{mL}$ for the $\mathrm{WB}$ and $1.55 \mathrm{mg}$ GAE per $\mathrm{mL}$ for the $\mathrm{CB}$, an $\mathrm{EC}_{50}$ increase of $56 \%$ and $23 \%$, respectively, indicating a lower level of cytotoxicity than in undigested fruits. HepG2 cells, when exposed to undigested and digested blueberry (Vaccinium angustifolium) samples, showed a cytotoxicity decrease of $85 \% .^{12}$ In digested Chinese bayberry (Myrica rubra) extracts, the cytotoxicity was $44-60 \%$ lower than that in undigested extracts. ${ }^{98}$ These studies are in agreement with our results, given that an increase in some free phenolic acids was observed following GID. This means that the degradation of large phenolics (e.g. tannins and flavonoids) and the increase in small phenolics (e.g. phenolic acids) in "chyle" during GID, may favor an increase in cytotoxicity in both Caco-2 and HepG2 cell lines.

3.5.2 Cellular antioxidant activity. The undigested samples of WB and CB showed a fluorescence inhibition rate of $85.88 \%$ and $78.70 \%$, respectively, compared with the quercetin control; these values are statistically different $(p<0.05)$ from each other (Table 4). The $\mathrm{IP}_{120} \mathrm{~min}$ samples indicated fluorescence inhibition of $58.39 \%$ in $\mathrm{WB}$ and $43.49 \%$ in $\mathrm{CB}$, with significant differences $(p<0.05)$ between both digestates and the undigested samples. In summary, the GID of WB and CB samples produced $32 \%$ and $45 \%$ less CAA, respectively, than for undigested fruits.

As reflected in the cytotoxicity of the blueberry to HepG2 cells, Jiao et al. ${ }^{12}$ reported a decrease of $85 \%$ of CAA at the end of GID; they also reported a strong correlation with the TPC and cytotoxicity. These results are consistent with those reported by Huang et al. ${ }^{98}$ and Boaventura et $a l .{ }^{96}$ for Myrica rubra and Ilex paraguariensis, respectively. According to Huang et al., ${ }^{98}$ the CAA of Chinese bayberry pomace improved after GID. However, in contrast with these authors' findings, we observed inhibition in CAA with GID, maybe because we used whole fruits rather than a fruit extract. During digestion, phenolics are metabolized and they can exhibit bioactivity while interacting with the gut epithelial surface. ${ }^{58}$

The CAA assay evaluates the ability of an antioxidant to interrupt the reaction between ROO (generated by AAPH) and a target probe. $^{35}$ It has gained importance in recent years because it provides more relevant information on antioxidant mechanisms in experimental cells lines than in in vitro (chemical) AOX assays. This method considers some aspects related to the take up, metabolism and location of antioxidants within cells, making it a potent tool for comparison in conjunction with in vivo AOX testing. ${ }^{35}$ Nevertheless, it is recommended to highlight the physiological relevance of CAA over other cellular and in vitro AOX assays.

3.5.3 Cellular oxidative stress. Intracellular oxidative damage related to the formation of reactive oxygen species (ROS) in the undigested samples of $\mathrm{WB}$ and $\mathrm{CB}$ showed an inhibition of $72.53 \%$ and $38.87 \%$, respectively, with significant differences $(p<0.05)$ between these values (Table 4$)$. The values reported at $\mathrm{IP}_{120}$ min indicated an inhibition of $36.95 \%$ in $\mathrm{WB}$ and only $5.37 \%$ in $\mathrm{CB}$, with a significant difference between them $(p<0.05)$. This means that, after GID, the capacity to decrease ROS formation in Caco- 2 cells of blackberry digestates was drastically inhibited, by about $50.05 \%$ in WB and by up to $86.14 \%$ in CB. Also, although the capacity to inhibit the formation of intracellular ROS decreased after GID, the pattern was not the same in WB and CB. Arango-Varela et $a l .{ }^{99}$ observed a reduction in ROS of $63-78 \%$ in samples of the Andes berry (Vaccinium meridionale), which was attributed to the presence of phenolics with different molecular weights. According to this, anthocyanidins (like cyanidin chloride) have greater ROS-synthesis inhibitory activity than small phenolics (like gallic acid). Nevertheless, the inhibition of ROS-synthesis by digested samples rich in phenolics is still limited.

The cellular oxidative stress assay evaluates the ability of an antioxidant to prevent the formation of oxidative sub-products in cells when they are exposed to a stress inductor (i.e.

Table 4 Cellular bioactivity of WB and CB fruits subjected to simulated in vitro digestion by the INFOGEST protocol

\begin{tabular}{|c|c|c|c|c|}
\hline \multirow[b]{2}{*}{ Cellular assay } & \multicolumn{2}{|l|}{ Before GID } & \multicolumn{2}{|l|}{ After GID } \\
\hline & WB & $\mathrm{CB}$ & WB & $\mathrm{CB}$ \\
\hline \multicolumn{5}{|l|}{ Caco- 2 cells } \\
\hline Cytotoxicity $\left(\mathrm{EC}_{50}, \mathrm{mg}\right.$ GAE per mL) & $0.50 \pm 0.04^{\mathrm{c}}$ & $1.20 \pm 0.07^{\mathrm{b}}$ & $1.14 \pm 0.08^{\mathrm{b}}$ & $1.55 \pm 0.07^{\mathrm{a}}$ \\
\hline $\mathrm{CAA}^{a}(\%)$ & $85.88 \pm 7.30^{\mathrm{a}}$ & $78.70 \pm 2.61^{\mathrm{b}}$ & $58.39 \pm 2.80^{c}$ & $43.49 \pm 0.00^{\mathrm{d}}$ \\
\hline $\operatorname{FIR}^{a}(\%)$ & $72.53 \pm 6.71^{\mathrm{a}}$ & $38.87 \pm 4.23^{\mathrm{b}}$ & $36.95 \pm 2.62^{\mathrm{b}}$ & $5.37 \pm 1.06^{\mathrm{c}}$ \\
\hline
\end{tabular}

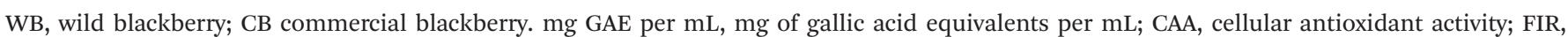

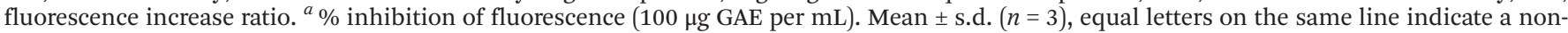
statistical difference $(p<0.05)$. 
$\left.\mathrm{H}_{2} \mathrm{O}_{2}\right) \cdot{ }^{36}$ Cellular oxidative stress has been linked to various degenerative diseases. ${ }^{36}$ Phenolics from berries and other plant sources help to prevent the formation of intracellular ROS in the Caco-2 cell model, as well in RAW 264.7 macrophages. ${ }^{56,99,100}$ Small phenolic acids, like those found in blackberry digestates, reduce oxidative stress induced by ROS in Caco-2 cells. ${ }^{101,102}$ Therefore, the metabolites of these anthocyanins and flavanols may play a key role in radical scavenging activity at the intestinal epithelium by direct interaction between ROS and phenolic acids. However, phenolic metabolites might upregulate the activation of the Nrf2/Keap1-ARE signaling pathway, an endogenous cellular antioxidant system related to the production of self-antiradical cell enzymes like glutathione reductase and oxidase in gut epithelial cells. ${ }^{102}$

\section{Conclusions}

Wild blackberries are underutilized fruits with a high content and large diversity of polyphenols. Despite the fact that WB samples had $70 \%$ less TPC than $\mathrm{CB}$ at $\mathrm{IP}_{120 \text { min }}$ (68\% less), WB still showed higher TPC than CB in the final digestate. Similar behavior was observed for TAC, where the TAC of WB was 75\% lower at $\mathrm{IP}_{120 \text { min }}$, but statistically $(p<0.05)$ higher than that of CB with $72 \%$ lower TAC at the end of GID. Several anthocyanins resisted the hostile environment of the gastrointestinal tract during digestion, including Cy-3-glu, Cy-3-rut, Cy-3-xylrut, Dp-3-(6-p-cou)-glu and Pt-3-glu, as well some flavanols such as epicatechin, Qc-3-glu, Qc-3-glur and Kf-3-glur. In contrast, the concentrations of many phenolic acids, such as gallic, vanillic, $p$-coumaric and ferulic acids, increases following digestion, which suggests that the catabolism of anthocyanins, flavanols and tannins may result in an increase in free phenolic acids in the digestive matrix.

The ORAC and ABTS assays showed that $\mathrm{WB} \mathrm{IP}_{120}$ min digestate had an AOX of $>50 \%$ after GID, compared with an AOX of $<50 \%$ for CB. The DPPH results also indicated that AOX was $>50 \%$; however, after GID, AOX values were statistically ( $p>$ 0.05) similar for undigested $\mathrm{CB}$ and digested WB. The $\beta$-carotene bleaching activity and reducing power methods showed a less significant decrease in $\mathrm{CB}$ than in $\mathrm{WB} \mathrm{IP}_{120}$ min digestates. However, the cytotoxicity of WB to Caco-2 cells was more inhibited than that of $\mathrm{CB}$ after GID. At the same time, the CAA of digested blackberries showed a statistically significant decrease $(p<0.05)$ of $48 \%$ in $\mathrm{WB}$ and $56 \%$ in CB following GID. Finally, the inhibition of the ROS-synthesis capacity in Caco-2 cells decreased by $50 \%$ in $\mathrm{WB}^{\mathrm{IP}_{120} \mathrm{~min}}$, and up to $86 \%$ in $\mathrm{CB} \mathrm{IP}_{120} \mathrm{~min}$. WB polyphenols exhibited similar biotransformations to those of $\mathrm{CB}$ phenolics during GID. However, certain particularities, such as the higher increase in many antioxidant free phenolic acids, suggest that WB provide better antioxidant effects than $\mathrm{CB}$. The results also indicate that bioaccessible phenolics from WB may have a higher bioavailability and bioactivity in the human body than CB polyphenols. Therefore, WB could be considered an emerging food with potential health benefits.

\section{Author contributions}

Conceptualization: O.A.S.-V. and A.J.H.-Á.; methodology: O.A. S.-V. and M. Mulero; investigation: O.A.S.-V. and M. Mulero; data curation: O.A.S.-V. and Y.A.; writing - original draft: O.A. S.-V. and A.J.H.-Á; supervision: E.O.C.-R. and A.J.H.-Á.; writing - editing: E.O.C.-R., M. Mondor and A.J.H.-Á.; validation: M. Mondor. and Y.A.; resources: Y.A.

\section{Conflicts of interest}

The authors declare that they have no known competing financial interests or personal relationships that could have impacted on the work reported in this paper.

\section{Acknowledgements}

Thanks are due to Barbara Bisakowski from the St-Hyacinthe Research and Development Centre, Agriculture and Agri-Food Canada, for her assistance with the INFOGEST protocol. Also special thanks to students Justine Vennat from La Rochelle Université and Alexandra Lanche from Université de Lorraine, for their valuable laboratory assistance. Oscar Abel SánchezVelázquez's scholarship was provided by the Consejo Nacional de Ciencia y Tecnología (CONACYT) through doctoral scholarship 504305.

\section{References}

1 B. L. Moreno-Medina, F. Casierra-Posada and J. Cutler, Phytochemical composition and potential use of Rubus, species, Gesunde Pflanzen, 2018, 70, 65-74.

2 J. Rzedowski, La Familia Rosaceae en México, Polibotánica, 2021, 51, 1-16.

3 O. A. Sánchez-Velázquez, E. O. Cuevas-Rodríguez, C. Reyes-Moreno, E. Y. Ríos-Iribe, A. J. Hernández-Álvarez, L. León-López and J. Milán-Carrillo, Profiling modifications in physicochemical, chemical and antioxidant properties of wild blackberry (Rubus sp.) during fermentation with EC 1118 yeast, J. Food Sci. Technol., 2021, 1-12.

4 M. Jazić, Z. Kukrić, J. Vulić and D. Četojević-Simin, Polyphenolic composition, antioxidant and antiproliferative effects of wild and cultivated blackberries (Rubus fruticosus, L.) pomace, Int. J. Food Sci. Technol., 2019, 54, 194-201.

5 Y. J. Surh, Cancer chemoprevention with dietary phytochemicals, Nature, 2003, 3, 768-780.

6 I. Fernandes, C. Marques, A. Évora, A. Faria, C. Calhau, N. Mateus and V. de Freitas, Anthocyanins: Nutrition and Health, in Bioactive Molecules in Food, ed. J. M. Mérillon and K. Ramawat, Reference Series in Phytochemistry, Springer, Cham. Switzerland, 1st edn, 2018, pp. 1-37.

7 M. Alminger, A.-M. Aura, T. Bohn, C. Dufour, S. N. El, A. Gomes, M. C. Martínez-Cuesta, G. J. McDougall, 
T. Requena and C. N. Santos, In Vitro Models for Studying Secondary Plant Metabolite Digestion and Bioaccessibility, Compr. Rev. Food Sci. Food Saf., 2014, 13(4), 413-436.

8 M. Zia-Ul-Haq, M. Riaz, V. De Feo, H. Jaafar and M. Moga, Rubus Fruticosus L.: Constituents, Biological Activities and Health Related Uses, Molecules, 2014, 19(8), 1099811029.

9 G. T. Sigurdson and M. M. Giusti, The stability and absorption of anthocyanins in the mouth, in Anthocyanins from natural sources: Exploiting targeted delivery for improved health, ed. M. S.-L. Brooks and G. B. Celli, The Royal Society of Chemistry, London, United Kingdom, 1st edn, 2019, ch. 7, pp. 186-215.

10 J. Montes-Ávila, G. López-Angulo and F. Delgado-Vargas, Tannins in Fruits and Vegetables: Chemistry and Biological Functions, in Fruit and Vegetable Phytochemicals, ed. E. M. Yahia, 2018.

11 M.-J. Bermúdez-Soto, F.-A. Tomás-Barberán and M.-T. García-Conesa, Stability of polyphenols in chokeberry (Aronia melanocarpa) subjected to in vitro, gastric and pancreatic digestion, Food Chem., 2007, 102, 865-874.

12 X. Jiao, B. Li, Q. Zhang, N. Gao, X. Zhang and X. Meng, Effect of in vitro-simulated gastrointestinal digestion on the stability and antioxidant activity of blueberry polyphenols and their cellular antioxidant activity towards HepG2 cells, Int. J. Food Sci. Technol., 2018, 53(1), 61-71.

13 D. Ryu and E. Koh, Stability of anthocyanins in bokbunja (Rubus occidentalis L.) under in vitro gastrointestinal digestion, Food Chem., 2018, 267, 157-162.

14 H. E. Khoo, A. Azlan, S. T. Tang and S. M. Lim, Anthocyanidins and anthocyanins: colored pigments as food, pharmaceutical ingredients, and the potential health benefits, Food Nutr. Res., 2017, 61(1), 1361779.

15 A. Osete-Alcaraz, A. B. Bautista-Ortín and E. Gómez-Plaza, The Role of Soluble Polysaccharides in Tannin-Cell Wall Interactions in Model Solutions and in Wines, Biomolecules, 2019, 10(1), 36.

16 O. A. Sánchez-Velázquez, Identificación de Compuestos Bioactivos Aislados de Dos Especies de Zarzamoras Silvestres (Rubus liebmannii Focke y Rubus palmeri Rydb) del Estado de Sinaloa $y$ su Efecto Antioxidante y Prooxidante sobre Líneas Celulares de Cáncer, Thesis of Master Degree, Universidad Autónoma de Sinaloa, Culiacan, Sinaloa, México, June 27th, 2016.

17 A. Brodkorb, L. Egger, M. Alminger, P. Alvito, R. Assunçao, S. Balance, T. Bohn, C. Bourlieu-Lacanal, R. Boutrou, F. Carrière, A. Clemente, M. Corredig, D. Dupont, C. Dufour, C. Edwards, M. Golding, S. Karakaya, B. Kirkhus, S. Le Feunteun, U. Lesmes, A. Macierzanka, A. Mackie, C. Martins, S. Marze, D. J. McClements, O. Ménard, M. Minekus, R. Portmann, C. Santos, I. Souchon, R. P. Singh, G. Vegarud, M. S. J. Wickham, W. Weitschies and I. Recio, INFOGEST static in vitro simulation of gastrointestinal food digestion, Nat. Protoc., 2019, 4, 991-1014.
18 S. Passamonti, Role of the stomach in anthocyanin absorption, in Anthocyanins from natural sources: Exploiting targeted delivery for improved health, ed. M. S.-L. Brooks and G. B. Celli, The Royal Society of Chemistry, London, United Kindom, 1st edn, 2019, ch. 8, pp. 216-246.

19 U. Shabbir, M. Rubab, E. B.-M. Daliri, R. Chelliah, A. Javed and D.-H. Oh, Curcumin, Quercetin, Catechins and Metabolic Diseases: The Role of Gut Microbiota, Nutrients, 2021, 13, 206.

20 A. Gil-Izquierdo, M. I. Gil, F. Ferreres and F. TomásBarberán, In vitro availability of flavonoids and other phenolics in orange juice, J. Agric. Food Chem., 2001, 49, 1035-1041.

21 G. J. McDougall, P. Dobson, P. Smith, A. Blake and D. Stewart, Assessing potential bioavailability of raspberry anthocyanins using an in vitro, digestion system, J. Agric. Food Chem., 2005, 53, 5896-5904.

22 V. L. Singleton, R. Orthofer and R. M. Lamuela-Raventos, Analysis of total phenols and other oxidation substrates and antioxidants by means of Folin-Ciocalteu Reagent, Methods Enzymol., 1999, 299, 152-178.

23 J. Lee, R. W. Durst and R. E. Wrolstad, Determination of Total Monomeric Anthocyanin Pigment Content of Fruit Juices, Beverages, Natural Colorants, and Wines by the $\mathrm{pH}$ Differential Method: Collaborative Study, J. AOAC Int., 2005, 88(5), 1269-1278.

24 L. Iglesias-Carres, A. Mas-Capdevila, L. Sancho-Pardo, F. I. Bravo, M. Mulero, B. Muguerza and A. Arola-Arnal, Optimized extraction by response surface methodology used for the characterization and quantification of phenolic compounds in whole red grapes (Vitis vinifera), Nutrients, 2018, 10(12), 1931.

25 N. Ortega, A. Macià, M.-P. Romero, J. Reguant and M.-J. Motilva, Matrix composition effect on the digestibility of carob flour phenols by an in vitro digestion model, Food Chem., 2011, 124(1), 65-71.

26 M. Leopoldini, T. Marino, N. Russo and M. Toscano, Antioxidant properties of phenolic compounds: H-atom versus electron transfer mechanism, J. Phys. Chem. A, 2004, 108, 4916-4922.

27 S. Skrovankova, D. Sumczynski, J. Mlcek, T. Jurikova and J. Sochor, Bioactive compounds and antioxidant activity in different types of berries, Int. J. Mol. Sci., 2015, 16, 24673-24706.

28 M. Antolovich, P. D. Prenzler, E. Patsalides, S. McDonald and K. Robards, Methods for testing antioxidant activity, Analyst, 2001, 127(1), 183-198.

29 İ. Gulcin, Antioxidants and antioxidant methods: an updated overview, Arch. Toxicol., 2020, 94(3), 651-715.

30 B. Ou, M. Hampsch-Woodill and R. L. Prior, Development and validation of an improved oxygen radical absorbance capacity assay using fluorescein as the fluorescent probe, J. Agric. Food Chem., 2001, 49, 4619-4626.

31 R. Sánchez-Vioque, M. F. Rodriguez-Condea, J. V. ReinaUrenaa, M. A. Escolano-Terceroa, D. Herraiz-Penalvera 
and O. Santana-Méridasa, In vitro antioxidant and metal chelating properties of corm, tepal and leaf from saffron (Crocus sativus L.), Ind. Crops Prod., 2012, 39, 149-153.

32 R. Re, N. Pellegrini, A. Proteggente, A. Pannala, M. Yang and C. Rice-Evans, Antioxidant activity applying an improved ABTS radical cation decolorization assay, Free Radicals Biol. Med., 1999, 26(9-10), 1231-1237.

33 G. J. Marco, A rapid method for evaluation pf antioxidants, J. Am. Oil Chem. Soc., 1968, 45, 594-598.

34 J. Carrasco-Castilla, A. J. Hernandez-Alvarez, C. JimenezMartinez, C. Jacinto-Hernandez, M. Alaiz, J. Giron-Calle, J. Vioque and G. Davila-Ortiz, Antioxidant and metal chelating activities of peptide fractions from phaseolin and bean protein hydrolysates, Food Chem., 2012, 135, 17891795.

35 M. E. Kellett, P. Greenspan and R. B. Pegg, Modification of the cellular antioxidant activity (CAA) assay to study phenolic antioxidants in a Caco-2 cell line, Food Chem., 2018, 244, 359-363.

$36 \mathrm{H}$. Wang and J. A. Joseph, Quantifying cellular oxidative stress by dichlorofluorescein assay using microplate reader, Free Radicals Biol. Med., 1999, 27, 612-616.

37 E. M. Coates, G. Popa, C. I. Gill, M. J. McCann, G. J. McDougall, D. Stewart and I. Rowland, Colon-available raspberry polyphenols exhibit anti-cancer effects on in vitro models of colon cancer, J. Carcinog., 2007, 6, 4.

38 M. S. Gião, S. Gomes, A. R. Madureira, A. Faria, D. Pestana, C. Calhau, M. E. Pintado, I. Azevedo and F. X. Malcata, Effect of in vitro digestion upon the antioxidant capacity of aqueous extracts of Agrimonia eupatoria, Rubus idaeus, Salvia sp. and Satureja montana, Food Chem., 2012, 131, 761-767.

39 W. Chen, H. Su, Y. Xu, T. Bao and X. Zheng, Protective effect of wild raspberry (Rubus hirsutus Thunb.) extract against acrylamide-induced oxidative damage is potentiated after simulated gastrointestinal digestion, Food Chem., 2016, 196, 943-952.

40 W. Chen, Y. Xu, L. Zhang, Y. Li and X. Zheng, Wild raspberry subjected to simulated gastrointestinal digestion improves the protective capacity against ethyl carbamateinduced oxidative damage in Caco-2 cells, Oxid. Med. Cell Longev., 2016, 2016, 3297363.

41 A. M. Dantas, I. M. Mafaldo, P. M. de L. Oliveira, M. dos S. Lima, M. Magnani and G. da S. C. Borgess, Bioaccessibility of phenolic compounds in native and exotic frozen pulps explored in Brazil using a digestion model coupled with a simulated intestinal barrier, Food Chem., 2018, 274, 202-214.

42 G.-I. Hidalgo and M. Almajano, Red Fruits: Extraction of Antioxidants, Phenolic Content, and Radical Scavenging Determination: A Review, Antioxidants, 2017, 6(1), 7.

43 T. Bohn, F. Carriere, L. Day, A. Deglaire, L. Egger, D. Freitas, M. Golding, S. Le Feunteun, A. Macierzanka, O. Menard, B. Miralles, A. Moscovici, R. Portmann, I. Recio, D. Rémond, V. Santé-Lhoutelier, T. J. Wooster, U. Lesmes, A. R. Mackie and D. Dupont, Correlation between in vitro and in vivo data on food digestion. What can we predict with static in vitro digestion models?, Crit. Rev. Food Sci. Nutr., 2017, 1-23.

44 S. Pinteus, J. Silva, C. Alves, A. Horta, O. Thomas and R. Pedrosa, Antioxidant and Cytoprotective Activities of Fucus spiralis Seaweed on a Human Cell in Vitro, Model, Int. J. Mol. Sci., 2017, 18(2), 292.

45 Y. Qin, L. Wang, Y. Liu, Q. Zhang, Y. Li and Z. Wu, Release of phenolics compounds from Rubus idaeus L. dried fruits and seeds during simulated in vitro digestion and their bio-activities, J. Funct. Foods, 2018, 46, 57-65.

46 L. Tavares, I. Figueira, D. Macedo, G. J. McDougall, M. C. Leitão, H. L. A. Vieira, D. Stewart, P. M. Alves, R. B. Ferreira and C. N. Santos, Neuroprotective effect of blackberry (Rubus sp.) polyphenols is potentiated after simulated gastrointestinal digestion, Food Chem., 2012, 131(4), 1443-1452.

47 L. Lavefve, L. R. Howard and F. Carbonero, Berry polyphenols metabolism and impact on human gut microbiota and health, Food Funct., 2019, 11(1), 45-65.

48 G. Azofeifa, S. Quesada, A. Pérez, F. Vaillant and A. Michel, Effect of an In Vitro Digestion on the Antioxidant Capacity of a Microfiltrated Blackberry Juice (Rubus adenotrichos), Beverages, 2018, 4(2), 30.

49 J. Correa-Betanzo, E. Allen-Vercoe, J. McDonald, K. Schroeter, M. Corredig and G. Paliyath, Stability and biological activity of wild blueberry (Vaccinium angustifolium) polyphenols during simulated in vitro gastrointestinal digestion, Food Chem., 2014, 165, 522-531.

50 A. M. O'Sullivan, Y. C. O'Callaghan, T. P. O'Connor and N. M. O'Brien, Comparison of the Antioxidant Activity of Commercial Honeys, Before and After In vitro Digestion, Polish J. Food Nutr. Sci., 2013, 63(3), 167-171.

51 P. Markakis and L. Jurd, Anthocyanins and their stability in foods, CRC Crit. Rev. Food Technol., 1974, 4(4), 437-456.

52 A. Patras, N. P. Burton, S. D. Pieve and F. Butler, Impact of high pressure processing on total antioxidant activity, phenolic, ascorbic acid, anthocyanin content and colour of strawberry and blackberry purées, Innov. Food Sci. Emerg. Technol., 2009, 10(3), 308-313.

53 J. He and M. M. Giusti, Anthocyanins: Natural Colorants with Health-Promoting Properties, Annu. Rev. Food Sci. Technol., 2010, 1, 163-187.

54 J. Lee, M. Dosset and C. E. Finn, Rubus, fruit phenolic research: the good, the bad, and the confusing, Food Chem., 2012, 130, 785-796.

55 G. J. McDougall, N. N. Kulkarni and D. Stewart, Current developments on the inhibitory effects of berry polyphenols on digestive enzymes, BioFactors, 2008, 34(1), 73-80.

56 Y. Luo, Q. Zhuan, J. Li, X. Du, Z. Huang, Y. Hou and X. Fu, Procyanidin B2 Improves Oocyte Maturation and Subsequent Development in Type 1 Diabetic Mice by Promoting Mitochondrial Function, Reprod. Sci., 2020, 27(12), 22112222.

57 R. Mattioli, A. Francioso, L. Mosca and P. Silva, Anthocyanins: A Comprehensive Review of Their Chemical 
Properties and Health Effects on Cardiovascular and Neurodegenerative Diseases, Molecules, 2020, 25(17), 3809.

58 F. J. Olivas-Aguirre, S. Mendoza, E. Alvarez-Parrilla, G. A. Gonzalez-Aguilar, M. A. Villegas-Ochoa, J. T. J. Quintero-Vargas and A. Wall-Medrano, First-Pass Metabolism of Polyphenols from Selected Berries: A HighThroughput Bioanalytical Approach, Antioxidants, 2020, 9(4), 311.

59 E. F. Gris, E. A. Ferreira, L. D. Falcão and M. T. BordignonLuiz, Influence of ferulic acid on stability of anthocyanins from Cabernet Sauvignon grapes in a model system and a yogurt system, Int. J. Food Sci. Technol., 2007, 42(8), 992998.

60 T. K. McGhie and M. C. Walton, The bioavailability of anthocyanins: towards a better understanding, Mol. Nutr. Food Res., 2007, 51(6), 702-713.

61 T. Nurmi, J. Mursu, M. Heinonen, A. Nurmi, R. Hiltunen and S. Voutilainen, Metabolism of Berry Anthocyanins to Phenolic Acids in Humans, J. Agric. Food Chem., 2009, 57(6), 2274-2281.

62 R. M. De Ferrars, C. Czank, Q. Zhang, N. P. Botting, P. A. Kroon, A. Cassidy and C. D. Kay, The pharmacokinetics of anthocyanins and their metabolites in humans, Br. J. Pharmacol., 2014, 171(13), 3268-3282.

63 A. Stalmach, Bioavailability of Dietary Anthocyanins and Hydroxycinnamic Acids, in Polyphenols in Human Health and Disease, ed. R. R. Watson, V. R. Preedy and S. Zibadi, Academic Press, Glasgow, United Kindom, 1st edn, 2014, vol. 1, pp. 561-576.

64 J. P. E. Spencer, H. Schroeter, A. R. Rechner and C. RiceEvans, Bioavailability of Flavan-3-ols and Procyanidins: Gastrointestinal Tract Influences and Their Relevance to Bioactive Forms In Vivo, Antioxid. Redox Signal., 2001, 3(6), 1023-1039.

65 R. M. Hackman, J. A. Polagruto, Q. Y. Zhu, B. Sun, H. Fujii and C. L. Keen, Flavanols: digestion, absorption and bioactivity, Phytochem. Rev., 2007, 7(1), 195-208.

66 O. A. Sánchez-Velázquez, J. Montes-Ávila, J. MilánCarrillo, C. Reyes-Moreno, S. Mora-Rochín and E. O. Cuevas-Rodríguez, Characterization of tannins from two wild blackberries (Rubus, spp) by LC-ESI-MS/MS, NMR and antioxidant activity, J. Food Meas. Charact., 2019, 13, 2265-2274.

67 A. I. Martinez-Gonzalez, Á. G. Díaz-Sánchez, L. A. Rosa, C. L. Vargas-Requena, I. Bustos-Jaimes and A. E. AlvarezParrilla, Polyphenolic Compounds and Digestive Enzymes: In Vitro Non-Covalent Interactions, Molecules, 2017, $22(4), 669$.

68 M. Friedman and H. S. Jürgens, Effect of $\mathrm{pH}$ on the Stability of Plant Phenolic Compounds, J. Agric. Food Chem., 2000, 48(6), 2101-2110.

69 S. K. T. Seraglio, A. C. Valese, H. Daguer, G. Bergamo, M. S. Azevedo, P. Nehring, L. V. Gonzaga, R. Fett and A. C. O. Costa, Effect of in vitro gastrointestinal digestion on the bioaccessibility of phenolic compounds, minerals, and antioxidant capacity of Mimosa scabrella, Bentham honeydew honeys, Food Res. Int., 2017, 99, 670-678.

70 C. D. Agudelo, I. Luzardo-Ocampo, R. Campos-Vega, G. Loarca-Piña and M. E. Maldonado-Celis, Bioaccessibility during In Vitro Digestion and Antiproliferative Effect of Bioactive Compounds from Andean Berry, (Vaccinium meridionale Swartz) Juice, J. Agric. Food Chem., 2018, 66(28), 7358-7366.

71 I. Figueira, R. Menezes, D. Macedo, I. Costa and C. Nunes dos Santos, Polyphenols Beyond Barriers: A Glimpse into the Brain, Curr. Neuropharmacol., 2017, 15(4), 562-594.

72 E. Celep, M. Charehsaz, S. Akyüz, E. T. Acar and E. Yesilada, Effect of in vitro gastrointestinal digestion on the bioavailability of phenolic components and the antioxidant potentials of some Turkish fruit wines, Food Res. Int., 2015, 78, 209-215.

73 A. Gapski, T. M. Gomes, M. A. Bredun, N. E. FerreiraLima, F. K. Ludka, M. T. Bordignon-Luiz and V. M. Burin, Digestion behavior and antidepressant-like effect promoted by acute administration of blueberry extract on mice, Food Res. Int., 2019, 108618.

74 M. R. Olthof, P. C. H. Hollman and M. B. Katan, Chlorogenic Acid and Caffeic Acid Are Absorbed in Humans, J. Nutr., 2001, 131(1), 66-71.

75 F. Chen, G.-Q. Fan, Z. Zhang, R. Zhang, Z.-Y. Deng and D. J. McClements, Encapsulation of omega-3 fatty acids in nanoemulsions and microgels: Impact of delivery system type and protein addition on gastrointestinal fate, Food Res. Int., 2017, 100, 387-395.

76 A. Kosińska-Cagnazzo, S. Diering, D. Prim and W. Andlauer, Identification of bioaccessible and uptaken phenolic compounds from strawberry fruits in in vitro digestion/Caco-2 absorption model, Food Chem., 2015, 170, 288-294.

77 J. M. Lorenzo, M. Estévez, F. J. Barba, R. Thirumdas, D. Franco and P. E. S. Munekata, Polyphenols: Bioaccessibility and bioavailability of bioactive components, Innovative Therm. Non-Therm. Process., Bioaccessibility Bioavailability Nutr. Bioact. Compd., 2019, 309-332.

78 R. Bitsch, M. Netzel, S. Sonntag, G. Strass, T. Frank and I. Bitsch, Urinary Excretion of Cyanidin Glucosides and Glucuronides in Healthy Humans After Elderberry Juice Ingestion, J. Biomed. Biotechnol., 2004, 5, 343-345.

79 A. Tresserra-Rimbau, S. Castro-Barquero, F. Vitelli-Storelli, N. Becerra-Tomas, Z. Vázquez-Ruiz, A. Díaz-López, D. Corella, O. Castañer, D. Romaguera, J. Vioque, Á. M. Alonso-Gómez, J. Wärnberg, J. A. Martínez, L. SerraMajem, R. Estruch, F. J. Tinahones, J. Lapetra, X. Pintó, J. A. Tur, J. López-Miranda, L. García-Molina, M. DelgadoRodríguez, P. Matía-Martín, L. Daimiel, M. Rubín-García, J. Vidal, A. Galdon, E. Ros, F. J. Basterra-Gortari, N. Babio, J. V. Sorlí, Á. Hernáez, J. Konieczna, L. NotarioBarandiaran, L. Tojal-Sierra, J. Pérez-López, I. Abete, J. Álvarez-Pérez, J. C. Fernández-García, J. M. SantosLozano, A. Galera-Cusí, A. Julibert, M. Ruiz-Canela, 
R. Martinez-Lacruz, K. A. Pérez-Vega, A. M. GalmesPanades, C. Pastor-Polo, A. Moreno-Rodriguez, A. Gea, M. Fitó, R. M. Lamuela-Raventós and J. Salas-Salvadó, Associations between Dietary Polyphenols and Type 2 Diabetes in a Cross-Sectional Analysis of the PREDIMED-Plus Trial: Role of Body Mass Index and Sex, Antioxidants, 2019, 8(11), 537.

80 M. Kubota, C. Ishikawa, Y. Sugiyama, S. Fukumoto, T. Miyagi and S. Kumazawa, Anthocyanins from the fruits of Rubus croceacanthus and Rubus sieboldii, wild berry plants from Okinawa, Japan, J. Food Compost Anal, 2012, 28(2), 179-182.

81 A. B. Cerezo, E. Cuevas, P. Winterhalter, M. C. GarciaParrilla and A. M. Troncoso, Isolation, identification, and antioxidant activity of anthocyanin compounds in Camarosa strawberry, Food Chem., 2010, 123(3), 574-582.

82 C.-J. Chiang, H. Kadouh and K. Zhou, Phenolic compounds and antioxidant properties of gooseberry as affected by in vitro digestion, LWT-Food Sci. Technol., 2013, 51(2), 417-422.

83 N. Zhou, W. Zhu, F. Yang and K. Zhou, In vitro gastrointestinal digestion model to monitor the antioxidant properties and bioavailability of phenolic antioxidants from elderberry, React. Oxygen Species, 2016, 2, 421-431.

84 L. Ryan and S. L. Prescott, Stability of the antioxidant capacity of twenty-five commercially available fruit juices subjected to an in vitro digestion, Int. J. Food Sci. Technol., 2010, 45(6), 1191-1197.

85 S. Thomas-Valdés, C. Theoduloz, F. Jiménez-Aspee, A. Burgos-Edwards and G. Schmeda-Hirschmann, Changes in polyphenol composition and bioactivity of the native Chilean white strawberry (Fragaria chiloensis, spp. chiloensis f. chiloensis) after in vitro gastrointestinal digestion, Food Res. Int., 2018, 105, 10-18.

86 G. Litwinienko and K. U. Ingold, Abnormal solvent effects on hydrogen atom abstraction. 2. Resolution of the curcumin antioxidant controversy. The role of sequential proton loss electron transfer, J. Org. Chem., 2004, 69, 5888-5896.

87 M. Biela, J. Rimarčík, E. Senajová, A. Kleinová and E. Klein, Antioxidant action of deprotonated flavonoids: Thermodynamics of sequential proton-loss electron-transfer, Phytochem, 2020, 180, 112528.

88 M. C. Foti, C. Daquino and C. Geraci, Electron-transfer reaction of cinnamic acids and their methyl esters with the DPPH. radical in alcoholic solutions, J. Org. Chem., 2004, 69, 2309-2314.

89 E. Klein, V. Lukes and M. Ilcin, DFT/B3LYP study of tocopherols and chromans antioxidant action energetics, Chem. Phys., 2007, 336, 51-57.

90 M. F. Abu Bakar, N. A. Ismail, A. Isha and M. Ling, Phytochemical Composition and Biological Activities of Selected Wild Berries (Rubus moluccanus L., R. fraxinifolius Poir., and R. alpestris Blume), Evidence-Based Complementary Altern. Med., 2016, 1-10.

91 R. C. G. Corrêa, C. W. I. Haminiuk, L. Barros, M. I. Dias, R. C. Calhelha, C. G. Kato, V. G. Correa, R. M. Peralta and
I. C. F. R. Ferreira, Stability and biological activity of Merlot (Vitis vinifera) grape pomace phytochemicals after simulated in vitro gastrointestinal digestion and colonic fermentation, J. Funct. Foods, 2017, 36, 410-417.

92 R. L. Prior, X. L. Wu and K. Schaich, Standardized methods for the determination of antioxidant capacity and phenolics in foods and dietary supplements, J. Agric. Food Chem., 2005, 53, 4290-4302.

93 N. R. Mihailović, V. B. Mihailović, A. R. Ćirić, N. Z. Srećković, M. R. Cvijović and L. G. Joksović, Analysis of Wild Raspberries (Rubus idaeus L.): Optimization of the Ultrasonic-Assisted Extraction of Phenolics and a New Insight in Phenolics Bioaccessibility, Plant Foods Hum. Nutr., 2019, 74, 399-404.

94 G. E. Hirsch, M. Vizzotto, A. L. Aboy, A. T. Henriques and T. Emanuelli, Antioxidant activity of blackberry (Rubus, sp.) genotypes from the Southern Region of Brazil, Bol. Cent. Pesqui. Process. Aliment., 2013, 31(1), 83-98.

95 L. Barros, A. M. Carvalho, J. S. Morais and I. C. F. R. Ferreira, Strawberry-tree, blackthorn and rose fruits: Detailed characterization in nutrients and phytochemicals with antioxidant properties, Food Chem., 2010, 120(1), 247-254.

96 B. C. B. Boaventura, R. D. d. M. C. Amboni, E. L. da Silva, E. S. Prudencia, P. F. Di Pietro, L. G. Malta, R. M. Polinati and R. H. Liu, Effect of in vitro digestion of yerba mate (Ilex paraguariensis A. St. Hil.) extract on the cellular antioxidant activity, antiproliferative activity and cytotoxicity toward HepG2 cells, Food Res. Int., 2015, 77, 257263.

97 U. S. Sharma and A. Kumar, In vitro antioxidant activity of Rubus ellipticus fruits, J. Adv. Pharm. Technol. Res., 2011, 2(1), 47-50.

98 H. Huang, Y. Sun, S. Lou, H. Li and X. Ye, In vitro digestion combined with cellular assay to determine the antioxidant activity in Chinese bayberry (Myrica rubra Sieb. et Zucc.) fruits: a comparison with traditional methods, Food Chem., 2014, 146, 363-370.

99 S. S. Arango-Varela, I. Luzardo-Ocampo, M. E. MaldonadoCelis and R. Campos-Vega, Andean berry (Vaccinium meridionale, Swartz) juice in combination with Aspirin modulated anti-inflammatory markers on LPS-stimulated RAW 264.7 macrophages, Food Res. Int., 2020, 109541.

100 W. Chen, Y. Xu, L. Zhang, H. Su and X. Zheng, Blackberry subjected to in vitro gastrointestinal digestion affords protection against Ethyl Carbamate-induced cytotoxicity, Food Chem., 2016c, 212, 620-627.

101 N. Liang and D. D. Kitts, Chlorogenic acid isomers ameliorate oxidative stress in Caco- 2 cells treated with proinflammatory proteins by activating the Nrf2/Keap1-ARE signaling pathway, J. Agric. Food Chem., 2018, 66(42), 11008-11017.

102 X. Chen, J. H. Yang, S. S. Cho, J. H. Kim, J. Xu, K. Seo and S. H. Ki, 5-Caffeoylquinic acid ameliorates oxidative stress-mediated cell death via Nrf2 activation in hepatocytes, Pharm. Biol., 2020, 58(1), 999-1005. 